OPEN ACCESS

Edited by: Jacob A. Burack

McGill University, Canada

Reviewed by:

Thomas Lachmann,

Kaiserslautern University of

Technology, Germany

Natalie Ann Munro,

The University of Sydney, Australia

${ }^{*}$ Correspondence:

Antje von Suchodoletz

avs5@nyu.edu

Specialty section: This article was submitted to

Developmental Psychology,

a section of the journal

Frontiers in Psychology

Received: 31 January 2017 Accepted: 11 September 2017 Published: 26 September 2017

Citation:

von Suchodoletz A, Fäsche A and Skuballa IT (2017) The Role of Attention Shifting in Orthographic Competencies: Cross-Sectional Findings from 1st, 3rd, and 8th Grade

Students. Front. Psychol. 8:1665.

doi: 10.3389/fpsyg.2017.01665

\section{The Role of Attention Shifting in Orthographic Competencies: Cross-Sectional Findings from 1st, 3rd, and 8th Grade Students}

\author{
Antje von Suchodoletz ${ }^{1,2 *}$, Anika Fäsche ${ }^{1}$ and Irene T. Skuballa ${ }^{1,2}$ \\ ${ }^{1}$ Department of Psychology, University of Freiburg, Freiburg, Germany, ${ }^{2}$ Department of Psychology, New York University Abu \\ Dhabi, Abu Dhabi, United Arab Emirates
}

Attention shifting refers to one core component of executive functions, a set of higher-order cognitive processes that predict different aspects of academic achievement. To date, few studies have investigated the role of attention shifting in orthographic competencies during middle childhood and early adolescence. In the present study, 69 first-grade, 121 third-grade, and 85 eighth-grade students' attention shifting was tested with a computer version of the Dimensional Change Card Sort (DCCS; Zelazo, 2006). General spelling skills and specific writing and spelling strategies were assessed with the Hamburger Writing Test (May, 2002). Results suggested associations between attention shifting and various orthographic competencies that differ across age groups and by sex. Across all age groups, better attention shifting was associated with less errors in applying alphabetical strategies. In third graders, better attention shifting was furthermore related to better general spelling skills and less errors in using orthographical strategies. In this age group, associations did not differ by sex. Among first graders, attention shifting was negatively related to general spelling skills, but only for boys. In contrast, attention shifting was positively related to general spelling skills in eighth graders, but only for girls. Finally, better attention shifting was associated with less case-related errors in eighth graders, independent of students' sex. In sum, the data provide insight into both variability and consistency in the pattern of relations between attention shifting and various orthographic competencies among elementary and middle school students.

Keywords: attention shifting, spelling, cross-sectional study, elementary school children, secondary school children, gender differences, cohort study

\section{INTRODUCTION}

Attention shifting, one core component of executive functions, is defined as the ability to flexibly shift "back and forth between multiple tasks, operations, or mental sets" (Miyake et al., 2000, p. 55). Spelling mastery appears to require children to flexibly shift between multiple demands that are embedded in the process of transforming a spoken word into written symbols (Lubin et al., 2016). For example, recognizing smaller units of meaning and sound, retrieving the correct letter or letter combination for each sound, and finally writing the letter in the correct form requires the flexible 
shifting of attention (Aram et al., 2014; Blair and Raver, 2015). In addition, spelling requires one to shift between strategies, lexical and non-lexical strategies in particular, when decoding and spelling words (Sheriston et al., 2016).

The ability to voluntarily focus or shift attention as needed develops during the early elementary school years, between 7 and 9 years of age (Anderson, 2010). Attention shifting continues to improve throughout middle childhood and becomes relatively mature by the beginning of adolescence (Anderson, 2010). A variety of measures exist to assess attention shifting. However, only few can be used at different stages of the lifespan and across age groups, one of which is the computer-based version of the Dimensional Change Card Sort (DCCS; Zelazo, 2006). The DCCS requires participants to sort objects by two dimensions, color and shape. Preschool children are able to switch tasks as long as the stimuli vary along only one dimension (Diamond et al., 2005). As they grow older, accuracy on the DCCS increases, as children are able to switch from sorting by either color or shape to sorting by the other (Diamond et al., 2005). Most children are able to complete the DCCS accurately around the age of school entry (Diamond and Kirkham, 2005). However, there is evidence that, despite high accuracy rates in sorting objects by switching dimensions, attentional inertia persists. Diamond and Kirkham (2005) used a computer-based version of the DCCS with young adults (i.e., undergraduate college students in their early twenties). While the participants were able to switch sorting dimensions, their reaction time pattern was similar to the accuracy pattern among young children, i.e., reaction time was significantly slower when the sorting criterion changed (Diamond and Kirkham, 2005). Evidence that the computerbased version of the DCCS captures individual differences in attention shifting among children and adults suggests that the DCCS is an appropriate measure for investigating attention shifting at different stages of the life span and across a wide age range.

\section{The Acquisition of Spelling}

Spelling is an important prerequisite for competent writing and predicts a number of literacy outcomes at later ages (Temple et al., 1982; Aram et al., 2014). Spelling in alphabetic orthographies can be defined as the ability to transform a spoken word into written symbols on the page (Berninger et al., 1996). Learning to spell means being able to map phonemes (i.e., units of speech) onto letters (i.e., units of print), and to understand that letters primarily represent sounds in language rather than meaning (McBride-Chang, 2004; Aram et al., 2014). Three sequential schemes of early spelling development have been suggested: graphic, writing-like, and symbolic writing (Levin and Bus, 2003). Writing in the graphic phase is characterized by the spontaneous production of small graphic forms and shapes. As soon as children know that letters, not pictures or shapes, represent print units, they move to the next phase, although they might not yet understand the relation between letter names and their sounds (McBride-Chang, 2004). During the preschool period, children discover writing-like features (Temple et al., 1982). Once they reach the phase of symbolic writing children are able to use symbolic units and move from phonetic writing to conventional spelling (Temple et al., 1982; Levin and Bus, 2003).

Although, in alphabetic orthographies letters typically map onto phonemes, the writing system also contains non-alphabetic aspects (Nagy et al., 2006). As children learn to spell, they acquire knowledge about morphology and orthographic patterns. Such knowledge is successively incorporated in children's attempts to spell as they learn to conform to the standard spelling rules of their language (McBride-Chang, 2004). Most research on spelling acquisition has focused on the early childhood years. However, spelling development continues after school entry across all years of schooling when children are increasingly confronted with words of irregular spelling patterns, abstract words, and complex clause types that require specialized knowledge of spelling rules (Temple et al., 1982; McBrideChang, 2004; Christie and Derewianka, 2010). While children have some basic morphological knowledge as early as in first grade (Treiman and Cassar, 1996), their use of morphological strategies is still fragile and not reliably reflected in their spellings until after third grade (Nagy et al., 2006). Similarly, basic orthographic knowledge emerges early in spelling acquisition, i.e., in kindergarten and first grade (Treiman and Bourassa, 2000). It is not until the later school years, however, that children can reliably incorporate their knowledge about orthographical strategies in their spellings (Treiman and Bourassa, 2000). For example, knowledge of allowable consonant doublets (i.e., twoletter spellings that typically occur in the middle and at the end of words) emerges in first grade, but proficiency in applying knowledge of orthographic patterns is not reached until sixth grade and above (Cassar and Treiman, 1997; Treiman and Bourassa, 2000). However, spelling is typically studied from a word-level perspective, thus limiting conclusions about the role of morphology and knowledge of orthographic units in spelling.

\section{Attention Shifting and Spelling}

Early attention shifting supports young children's acquisition of precursor skills to the development of later spelling, such as letter/alphabet knowledge and print awareness (Blair and Razza, 2007; Bierman et al., 2008). As children grow older and enter formal schooling, attention shifting helps them to develop adaptive learning strategies and apply them flexibly to changing task demands. During the early elementary school years, children are increasingly confronted with non-alphabetic aspects of the writing system that require them to flexibly shift between several mental tasks, including retrieving the spelling of words from memory, applying orthographic patterns, or using phoneme-grapheme correspondence rules (Lubin et al., 2016). Although, various executive function components contribute to spelling acquisition, Lubin et al. (2016) found that attention shifting seems to be particularly predictive of spelling outcomes among elementary school children. Fourth-grade children were administered the Creature Counting subtest from the Test of Everyday Attention for Children (Manly et al., 1999) to measure attention shifting. The test requires children to use arrows as a cue to switch the direction of their counting. Spelling outcomes were assessed with a dictation test. After controlling for child age, sex, and nonverbal intelligence, executive function skills 
explained $19 \%$ of the variance in the spelling outcome. However, the findings indicated that only attention shifting significantly contributed to explaining the variance in children's spelling skills.

While the relation between attention shifting and literacy skills is well-established in samples of English-speaking children (Blair and Razza, 2007; Bierman et al., 2008), there is some evidence suggesting that associations might be different in other languages. Among French-speaking kindergarten children, for example, attention shifting and emergent literacy skills were not significantly associated (Monette et al., 2011). In another study with a sample of Dutch-speaking elementary school students, the relation between executive functions and reading was found to be negative (van der Sluis et al., 2007).

\section{Sex Differences in Spelling and Attention Shifting}

The sex achievement gap suggests that boys may be at greater risk for school difficulties than girls (Matthews et al., 2009; Rimm-Kaufman et al., 2009; DiPrete and Jennings, 2012; Wanless et al., 2013). Girls frequently outperform boys on a wide range of measures of school achievement across different learning domains. For reading, for example, girls' advantage corresponds to approximately one school year's progress [PISA ${ }^{1}$ 2009 study: Organization for Economic Co-operation and Development (OECD), 2010]. Girls also demonstrated higher writing competence (Pajares and Valiente, 1999) and written orthographic fluency (Berninger and Fuller, 1992) compared to boys. The pattern of sex differences in spelling skills among typically developing writers was also replicated in samples of children with dyslexia and their parent with dyslexia (Berninger et al., 2008a). In both samples, the male participants were consistently more impaired than their female counterparts in measures of spelling and orthographic skills. In search of an explanation, McGeown et al. (2013) argue that sex differences may be related to differences in girls' and boys' strategy preferences and their ability to use strategies effectively. Strategies may be specific to the learning domain (such as orthographical spelling strategies) or domain-general (such as executive functions). Individual differences in executive functions might be related to sex differences in orthographic competencies (Berninger et al., 2008b). Indeed, there is considerable research to suggest that girls may be more efficient at using executive functions (Wilson, 2003; Sabbagh et al., 2006; Matthews et al., 2009; Rimm-Kaufman et al., 2009; Wanless et al., 2013). Specifically, sex differences in attention shifting in favor of girls have been reported across age groups (Klenberg et al., 2001) and various measures of attention shifting (Klenberg et al., 2001; Wilson, 2003). Neuropsychological differences may underlie girls' advantage in attention shifting. Feng et al. (2011) found greater brain activation (interpreted as the use of more attention resources) for women compared to men when completing an attention shifting task among students in their early twenties (mean age in both groups was 21.9 years).

Together, these studies suggest that both spelling and attention shifting skills differ by sex. However, it remains unclear whether

\footnotetext{
${ }^{1}$ Program for International Student Assessment (PISA).
}

there are (a) sex differences in the relation between attention shifting and spelling, and whether (b) sex differences are similar or different across age groups. While some research suggests that the gap between boys and girls in executive functions increases from childhood to adolescence (Else-Quest et al., 2006; Matthews et al., 2009), other evidence indicates that boys could catch up in their executive function skills as they grow older (Gunzenhauser and von Suchodoletz, 2015).

\section{The Present Study}

The goal of the present study was to investigate whether attention shifting, one core component of executive functions, is equally important for orthographic competencies at different ages and for boys and girls. By using the same measure of attention shifting (a computer version of the DCCS) and gradeappropriate versions of the same spelling task in a sample of first, third, and eighth graders, the study aimed to provide new information on individual differences in attention shifting in middle childhood and early adolescence and its associations with spelling competencies. By doing so, we addressed gaps of prior research regarding differences in task characteristics that limited strong conclusions (Best et al., 2011; Cuevas et al., 2014). The selection of age groups was based on previous literature suggesting that voluntary attention shifting starts to emerge during the early elementary school years and becomes relatively mature by the beginning of adolescence (Anderson, 2010). Moreover, the contribution of attention shifting might depend on the specific outcome being measured. We therefore investigated general spelling skills as well as specific spelling skills, including alphabetical, orthographical, and morphological strategies. Understanding these associations can help to determine the extent to which attention shifting relates to which particular aspect of spelling.

Two research questions guided the present study: (1) Does attention shifting relate to orthographic competencies across all age groups? Specifically, we tested for cross-group invariance between first, third, and eighth graders. (2) Are there sex differences in the relation between attention shifting and orthographic competencies within each age group? We tested for cross-group invariance regarding sex within the samples of first, third, and eighth graders.

\section{METHODS}

\section{Participants and Procedure}

The participants were 275 school-aged children (51\% girls) from South-West Germany. Sixty-nine students were in Grade 1, 121 in Grade 3, and 85 in Grade 8. The students' mean age was 7.23 years in Grade $1(S D=0.39), 8.47$ years in Grade $3(S D=0.45)$, and 13.99 years in Grade $8(S D=0.40)$. All of the children were typically developing insofar that they were not enrolled in special education or special needs programs at their school. The first- and third-grade students were recruited from public primary schools; the eighth-grade students were recruited from the highest track of the public German secondary school system, i.e., the Gymnasium. For $78 \%$ of the first graders, $68 \%$ of the third 
graders, and $87 \%$ of the eighth graders, German was the primary language spoken at home.

To ensure that the protocol conforms to ethical standards, the study protocols in Grade 1 and Grade 3 were reviewed by the ethic committee of the German Psychological Association (DGPs). The study protocol in Grade 8 was reviewed by the Department of Psychology, Educational, and Developmental Psychology, at the University of Freiburg, Germany. All of the participants were recruited in their schools. Data was collected only from the children whose parents gave their informed written consent. Recruitment differences resulted in different sizes of the subsamples, in particular, the larger sample of the thirdgrade students. The third-grade students represent a randomly selected subsample drawn from a sample of over 700 students recruited from 56 classrooms in 34 schools (details can be found elsewhere: von Suchodoletz et al., 2015) who completed an additional data collection that included the measures used for the present analyses. The participants in Grade 1 were recruited from a database of families who participated in research when the children were younger (details can be found elsewhere: Gestsdottir et al., 2014) and had volunteered to be contacted for future research. The participants in Grade 8 were recruited specifically for this study.

The first-grade and third-grade students were tested at the local university, whereas the eighth-grade students were tested at their school. The children were administered the writing test first, followed by the computer version of the DCCS (presented on a laptop). It took between 30 and 45 min to complete the tasks. All of the participants received small incentives for their participation in the study.

\section{Measures Attention Shifting}

A computer-based version of the DCCS was used to measure attention shifting (DCCS; Diamond and Kirkham, 2005; Zelazo, 2006; Blankson and Blair, 2016). The DCCS has been shown to be a reliable and valid measure of attention shifting across a wide range of ages. For example, children's performance on the DCCS correlates with other measures of executive functions (Zelazo, 2006). The computer-based version of the DCCS has also been used with adult populations and has been proven to reliably capture individual differences in attention shifting (accuracy and reaction time) among adults (Diamond and Kirkham, 2005; von Suchodoletz et al., 2017).

Stimuli were presented on a laptop screen. The task required the participants to match a target stimulus presented at the top of the screen with two pictures that varied along two dimensions, i.e., color and shape, and appeared at the bottom corners of the screen. To match the pictures, the participants were instructed to press one of two yellow-marked keys on opposite sides of the laptop keyboard to indicate the location of their selection. In addition, a word (either color or shape) was presented at the top of the screen and spoken by a prerecorded voice to cue the participants to match the target picture with the correct corresponding picture on the bottom of the screen. Following a practice trial block, the participants were first asked to correctly sort the stimuli by one dimension (e.g., sort by shape; preswitch block) and then to switch and sort the stimuli by the other dimension (e.g., color; post-switch block). The final block consisted of mixed trials.

The participants' accuracy (i.e., percent correct) and reaction times (averaged for all correct trials) were recorded across the pre-switch, post-switch, and mixed-block. Trials in which the response was registered earlier than $200 \mathrm{~ms}$ or later than $3,000 \mathrm{~ms}$ after the onset of the stimulus were excluded from the analyses (Diamond and Kirkham, 2005). The mean percentage of correct responses, ranging between 85 and $95 \%$ across the participants (see Table 1), was similar to a study with undergraduate college students (Diamond and Kirkham, 2005). In the current study, attention shifting was measured in terms of inverse efficiency, i.e., average reaction time for all correct trials divided by accuracy (Spence et al., 2001; Schicke et al., 2009). Inverse efficiency scores provide a more psychometrically accurate representation of processing efficiency than using accuracy (i.e., proportion of correct responses) and reaction time as separate variables (Yang et al., 2014). The assumption underlying inverse efficiency scores is that "differences in reaction time performance would decrease if differences in accuracy [were] large but would remain the same if accuracy [were] identical" (Ding et al., 2014, p. 91). Inverse efficiency scores account for possible speed-accuracy trade-offs (i.e., slow responses, but less errors, and vice versa; Spence et al., 2001; Kitagawa and Spence, 2005; Holmes et al., 2007; Schicke et al., 2009). In the present data, a lower inverse efficiency score reflected better attention shifting skills.

\section{Orthographic Competencies}

The Hamburg Writing Test for first to ninth graders was used to measure orthographic competencies (German: Hamburger Schreibprobe 1-9; May, 2002). Age-appropriate versions for first, third, and eighth grade were used. The test requires the participants to write words and short sentences that are read aloud to them. The version for the eight graders also includes a text with mistakes to be corrected. The test has shown good re-test reliability $(0.92-0.99)$ and high predictive validity (for example, correlations with school essay writing of $r^{2}=0.78-0.82$; May, 2002). The test provides a profile for each student of the general spelling skills and specific spelling strategies, including alphabetical, orthographical, and morphological strategies. General spelling skills were measured by the number of correctly written words and graphemes. The test comprises 14 words/61 graphemes (Grade 1), 38 words/191 graphemes (Grade 3), and 49 words/339 graphemes (Grade 8) to compute general spelling ability. In the present data, higher scores reflected higher general spelling skills (i.e., more correct words and graphemes).

The alphabetical strategy refers to all word positions that can be spelled correctly by applying phonological rules. The number of positions in the different versions is 15 (Grade 1), 20 (Grade 3), and 30 (Grade 8). The orthographical strategy was coded for all word positions, for which knowledge of orthographic units, i.e., abstract letter-by-letter strings (Frith, 1985), is required. The orthographical strategy is distinguished from the alphabetical strategy as these word positions cannot be 
TABLE 1 | Descriptive statistics for variables of interest.

\begin{tabular}{|c|c|c|c|c|c|c|c|c|c|}
\hline & \multicolumn{3}{|c|}{ Grade 1} & \multicolumn{3}{|c|}{ Grade 3} & \multicolumn{3}{|c|}{ Grade 8} \\
\hline & $\begin{array}{c}\text { All } \\
(n=69) \\
M \\
(S D)\end{array}$ & $\begin{array}{c}\text { Girls } \\
(29) \\
M \\
(S D)\end{array}$ & $\begin{array}{c}\text { Boys } \\
(n=40) \\
M \\
(S D)\end{array}$ & $\begin{array}{c}\text { All } \\
(n=121) \\
M \\
(S D)\end{array}$ & $\begin{array}{c}\text { Girls } \\
(n=59) \\
M \\
(S D)\end{array}$ & $\begin{array}{c}\text { Boys } \\
(n=62) \\
M \\
(S D)\end{array}$ & $\begin{array}{c}\text { All } \\
(n=84) \\
M \\
(S D)\end{array}$ & $\begin{array}{c}\text { Girls } \\
(n=51) \\
M \\
(S D)\end{array}$ & $\begin{array}{c}\text { Boys } \\
(n=33) \\
M \\
(S D)\end{array}$ \\
\hline \multicolumn{10}{|l|}{ ATTENTION SHIFTING } \\
\hline Reaction time correct trials & $\begin{array}{c}1520.26 \\
(346.98)\end{array}$ & $\begin{array}{c}1637.40 \\
(359.27)\end{array}$ & $\begin{array}{c}1449.97 \\
(326.53)\end{array}$ & $\begin{array}{c}962.88 \\
(154.25)\end{array}$ & $\begin{array}{r}1003.49 \\
(145.12)\end{array}$ & $\begin{array}{c}923.06 \\
(153.88)\end{array}$ & $\begin{array}{c}686.18 \\
(133.18)\end{array}$ & $\begin{array}{c}676.27 \\
(136.67)\end{array}$ & $\begin{array}{c}701.51 \\
(128.14)\end{array}$ \\
\hline Percent correct & $\begin{array}{c}0.92 \\
(0.10)\end{array}$ & $\begin{array}{c}0.95 \\
(0.07)\end{array}$ & $\begin{array}{c}0.90 \\
(0.11)\end{array}$ & $\begin{array}{c}0.86 \\
(0.07)\end{array}$ & $\begin{array}{c}0.87 \\
(0.06)\end{array}$ & $\begin{array}{c}0.85 \\
(0.07)\end{array}$ & $\begin{array}{c}0.92 \\
(0.05)\end{array}$ & $\begin{array}{c}0.91 \\
(0.05)\end{array}$ & $\begin{array}{c}0.94 \\
(0.04)\end{array}$ \\
\hline Inverse efficiency score & $\begin{array}{c}1678.44 \\
(447.51)\end{array}$ & $\begin{array}{c}1752.20 \\
(485.13)\end{array}$ & $\begin{array}{r}1634.19 \\
(427.44)\end{array}$ & $\begin{array}{r}1127.35 \\
(215.82)\end{array}$ & $\begin{array}{c}1156.96 \\
(192.83)\end{array}$ & $\begin{array}{c}1098.31 \\
(234.48)\end{array}$ & $\begin{array}{c}747.57 \\
(146.33)\end{array}$ & $\begin{array}{c}746.86 \\
(152.22)\end{array}$ & $\begin{array}{c}748.66 \\
(139.03)\end{array}$ \\
\hline \multicolumn{10}{|c|}{ ORTHOGRAPHIC COMPETENCIES } \\
\hline Correct words & $\begin{array}{c}7.09 \\
(2.68)\end{array}$ & $\begin{array}{c}6.96 \\
(2.83)\end{array}$ & $\begin{array}{c}7.18 \\
(2.60)\end{array}$ & $\begin{array}{r}23.81 \\
(6.88)\end{array}$ & $\begin{array}{r}23.36 \\
(6.71)\end{array}$ & $\begin{array}{r}24.26 \\
(7.07)\end{array}$ & $\begin{array}{r}46.02 \\
(2.55)\end{array}$ & $\begin{array}{r}45.55 \\
(2.67)\end{array}$ & $\begin{array}{r}46.76 \\
(2.19)\end{array}$ \\
\hline Correct graphemes & $\begin{array}{r}48.28 \\
(9.18)\end{array}$ & $\begin{array}{r}49.00 \\
(7.04)\end{array}$ & $\begin{array}{c}47.77 \\
(10.47)\end{array}$ & $\begin{array}{r}175.50 \\
(10.63)\end{array}$ & $\begin{array}{c}174.28 \\
(10.23)\end{array}$ & $\begin{array}{c}176.72 \\
(10.96)\end{array}$ & $\begin{array}{r}335.79 \\
(4.29)\end{array}$ & $\begin{array}{r}335.02 \\
(5.14)\end{array}$ & $\begin{array}{r}336.97 \\
(2.04)\end{array}$ \\
\hline Alphabetical errors & $\begin{array}{c}1.51 \\
(2.05)\end{array}$ & $\begin{array}{c}1.61 \\
(2.17)\end{array}$ & $\begin{array}{c}1.45 \\
(1.99)\end{array}$ & $\begin{array}{c}1.47 \\
(1.65)\end{array}$ & $\begin{array}{c}1.29 \\
(1.50)\end{array}$ & $\begin{array}{c}1.66 \\
(1.78)\end{array}$ & $\begin{array}{c}0.56 \\
(0.61)\end{array}$ & $\begin{array}{c}0.63 \\
(0.56)\end{array}$ & $\begin{array}{c}0.45 \\
(0.67)\end{array}$ \\
\hline Orthographical errors & $\begin{array}{c}5.76 \\
(2.09)\end{array}$ & $\begin{array}{c}5.96 \\
(2.12)\end{array}$ & $\begin{array}{c}5.63 \\
(2.08)\end{array}$ & $\begin{array}{c}4.23 \\
(3.69)\end{array}$ & $\begin{array}{c}4.53 \\
(3.68)\end{array}$ & $\begin{array}{c}3.93 \\
(3.72)\end{array}$ & $\begin{array}{c}1.08 \\
(1.29)\end{array}$ & $\begin{array}{c}1.14 \\
(1.39)\end{array}$ & $\begin{array}{r}1.00 \\
(1.15)\end{array}$ \\
\hline Morphological errors & - & - & - & - & - & - & $\begin{array}{c}0.57 \\
(0.80)\end{array}$ & $\begin{array}{c}0.57 \\
(0.78)\end{array}$ & $\begin{array}{c}0.58 \\
(0.83)\end{array}$ \\
\hline Redundant elements & $\begin{array}{c}0.63 \\
(0.62)\end{array}$ & $\begin{array}{c}0.54 \\
(0.58)\end{array}$ & $\begin{array}{c}0.70 \\
(0.65)\end{array}$ & $\begin{array}{c}2.20 \\
(1.99)\end{array}$ & $\begin{array}{c}2.09 \\
(1.76)\end{array}$ & $\begin{array}{c}2.31 \\
(2.22)\end{array}$ & - & - & - \\
\hline Case-related errors & - & - & - & - & - & - & $\begin{array}{c}1.89 \\
(1.90)\end{array}$ & $\begin{array}{c}2.41 \\
(2.08)\end{array}$ & $\begin{array}{r}1.09 \\
(1.23)\end{array}$ \\
\hline
\end{tabular}

spelled correctly by applying alphabetical knowledge only (for example, a letter sound can be represented in several ways such as $x$ can be written as $x$, chs, $k s, c k s$, or $g s)$. The number of positions in the different versions is 10 (Grade 1), 15 (Grade 3), and 41 (Grade 8). The morphological strategy is based on the number of correctly spelled critical morpheme positions. These are letter groups in a word that require morphological rather than phonological or orthographical knowledge, for example vowel mutations. Because it is the most advanced strategy, it was only coded for the students in Grade 8. The total number of critical morpheme positions in the test was 28 . For analyses, the number of errors in applying each strategy were used as indicators for the specific writing and spelling strategies. Additionally, redundant elements (i.e., additional letters that indicate overgeneralization of alphabetic principles; for example, "ie" (Bield) instead of "i" (correct: Bild, in English: image, picture) were coded for the students in Grade 1 and Grade 3 and case-related errors (i.e., errors in capitalization of first letter in nouns and names) for the students in Grade 8, reflecting grade-appropriate expectations regarding the students' spelling. In the present data, higher scores indicated lower proficiency in applying specific spelling strategies, and more redundant elements and case-related errors in the students' writing samples.

\section{Analytic Strategy}

All analyses were conducted using the Bayesian approach with non-informative priors in Mplus 7.3 (Muthén and Muthén,
2014). The Bayes estimator compares an obtained value with a posterior probability distribution of predicted values (Kruschke, 2011). It is able to account for relatively small sample sizes and is robust to distributional assumptions of the estimated parameters of interest. Thus, it provides more trustworthy results than a traditional maximum likelihood estimator (Lee and Song, 2004; Muthén, 2010). In order to ensure model fit, we checked for convergence. Four chains were used in the Markov chain Monte Carlo estimation with a thinning option (20 draws) in order to control for autocorrelation. Good convergence is given, when the potential scale reduction factor keeps ranging around 1.00, while running the model with increasing numbers of iterations (Muthén, 2010). This was the case for all models analyzed and reported here. Meaningful estimates were indicated when the conditional confidence intervals of the fixed posterior distribution (Bayesian credibility intervals, BCI) for the estimates did not include zero. The BCIs can be interpreted similarly to those in traditional maximum likelihood estimation: A $90 \%$-BCI refers to a significance level of $p<0.10$, and a 95\%-BCI to a significance level of $p<0.05$.

The central goal of the present study was to test differences in the structural patterns of associations between two (i.e., between the boys and girls in Grade 3) or three subsamples (i.e., between the first, third, and eighth graders). Therefore, a multigroup approach with cross-group invariance testing was used. It allowed us to consider whether attention shifting contributed unique variance to different levels of spelling skills in each group 
separately. The advantage of cross-group invariance testing is that various structural parameters of interest (including means of predictors and outcomes, regression coefficients) in more than two subsamples can be tested against one another in one model. Compared to correlational analyses, this approach enables the investigation of relationships between multiple predictors and outcomes, accounts for possible co-variances between more than one indicator of interest, and considers several control variables that may potentially have a confounding effect on the relationship.

To examine cross-group invariance regarding age and sex in the prediction of orthographic competencies by the students' attention shifting (i.e., inverse efficiency score ${ }^{2}$ ), a three-step procedure was used for a correct estimation. Following the literature on measurement invariance analyses with Bayes (c.f., Van de Schoot et al., 2012; Muthén and Asparouhov, 2013), we have started with a full invariant model that sets all parameter equal across groups. Second, a full non-invariant model was tested that allowed variation in all parameter across groups. At the same time, difference tests for structural parameters of interest were included in order to identify meaningful differences between the groups. If a parameter was tested to be meaningfully different, then it was set free to vary between the groups in a third partial non-invariant model. The models were compared to each other in order to identify the best fitting model. For each set of analyses, the results of the best fitting model are reported in the Results section.

In more detail, the described procedure contained the following steps: In step 1, multiple regression models with configural equality constraints were estimated (i.e., full invariant models), holding all structural parameters of interest equal across the groups (i.e., regression coefficients, variable means). In step 2, non-invariant parameters were identified in models completely freeing the previously used equality constraints for the same parameters (i.e., full non-invariant models). For the analysis of cross-group invariance regarding age, difference tests between each group's structural parameter and its average across the three age groups (i.e., grade 1,3, and 8) were used for identification. For the analysis of structural invariance regarding sex within age groups, non-invariant parameters were identified with difference tests between the two sex groups (i.e., girls and boys). In step 3, models holding all but the non-invariant parameters identified in step 2 equal across groups (i.e., partial invariant models) were conducted and compared to the full invariant models of step 1 and the respective full non-invariant models of step 2. For comparison, the Deviance Information Criterion (DIC; Gelman et al., 2004) was used. That is, the Bayesian model comparison criterion that is defined analogously to the Akaike Information Criterion (AIC) generated in ML estimation. The DIC takes the complexity of the model into account, i.e., estimated as the effective number of parameters. Models with the smallest DIC values were preferred (Muthén, 2010). Thereby, the Bayes approach detects cross-group non-invariance similar to Wald

\footnotetext{
${ }^{2}$ All models were also estimated using reaction time as a measure of attention shifting. Results were found to be similar when using reaction time data.
}

statistics with maximum-likelihood estimation (Muthén and Asparouhov, 2013).

All of the analyses controlled for child age, sex ( $0=$ girls, 1 $=$ boys $)$ and home language $(0=$ child speaks German as home language, 1 = child speaks another language than German as primary home language). All variables were standardized (i.e., age, attention shifting, orthographic competence indicators) or dummy coded (i.e., sex, home language) before being entered into the analyses.

\section{RESULTS}

\section{Descriptive Statistics}

Descriptive statistics indicated that there was considerable variability in school-aged children's attention shifting and orthographic competencies, both within each grade and between grades (Table 1). The data showed that older students' attention shifting skills were higher than those of younger students (indicated by the smaller inverse efficiency scores among eighth graders compared to third graders and first graders). A similar pattern was found for students' word-level spelling and their proficiency to apply specific spelling strategies to their writing: Older students scored higher on the spelling test than younger students.

\section{The Role of Attention Shifting for Orthographic Competencies: Testing Age Invariance across Grade Levels}

The first research question (i.e., Are there differences in the relation between attention shifting and orthographic competencies across the age groups?) tested for cross-group invariance of the relation between attention shifting and spelling across grade levels. The first model was specified as a full invariant model and resulted in a DIC of 1066.07. Next, a full non-invariant model was run to identify meaningful differences between structural parameters of interest. The full non-invariant model resulted in a DIC of 1045.07. The differences in several structural parameters between the grade levels are reported in Table 2.

To further investigate these differences, a partial invariant model was run. The model released all parameters that were found to be different in the previous model but set all remaining parameters to be equal across grade levels. The DIC of the partial invariant model was lowest $(\mathrm{DIC}=1043.88)$. Therefore, this model was preferred over the full non-invariant model. The partial invariant model revealed a meaningful relation across all grade levels (i.e., invariant regression coefficient) between the students' attention shifting and their proficiency in using the alphabetical strategy in their writing (Figure 1, bottom). For all of the students, better attention shifting (indicated by a lower inverse efficiency score) was related to fewer errors in alphabetical spelling. Furthermore, differences across grade levels were identified (as indicated by variant regression coefficients; Table 3 and Figure 1). Meaningful relations emerged between the thirdgrade students' attention shifting and word-level spelling skills, and between attention shifting and the use of the orthographic 
TABLE 2 | Results of difference tests for structural age invariance analyses in the full non-invariant model.

\begin{tabular}{|c|c|c|c|c|c|c|c|c|c|}
\hline & \multicolumn{3}{|c|}{ Grade $1(n=69)$} & \multicolumn{3}{|c|}{ Grade $3(n=121)$} & \multicolumn{3}{|c|}{ Grade $8(n=84)$} \\
\hline & $\begin{array}{c}B \\
(S D)\end{array}$ & $\begin{array}{l}95 \% \\
\mathrm{BCI}\end{array}$ & $\begin{array}{c}90 \% \\
\mathrm{BCl}\end{array}$ & $\begin{array}{c}B \\
(S D)\end{array}$ & $\begin{array}{l}95 \% \\
\mathrm{BCl}\end{array}$ & $\begin{array}{l}90 \% \\
\mathrm{BCI}\end{array}$ & $\begin{array}{c}B \\
(S D)\end{array}$ & $\begin{array}{l}95 \% \\
\mathrm{BCl}\end{array}$ & $\begin{array}{l}90 \% \\
\mathrm{BCl}\end{array}$ \\
\hline \multicolumn{10}{|l|}{ REGRESSION COEFFICIENTS } \\
\hline IE score on correct words & $\begin{array}{c}\mathbf{0 . 1 3} \\
(0.05)\end{array}$ & $\begin{array}{l}0.04 \\
0.21\end{array}$ & $\begin{array}{l}0.06 \\
0.21\end{array}$ & $\begin{array}{r}-0.20 \\
(0.05)\end{array}$ & $\begin{array}{c}-0.30 \\
-0.11\end{array}$ & $\begin{array}{l}-0.28 \\
-0.12\end{array}$ & $\begin{array}{c}0.07 \\
(0.06)\end{array}$ & $\begin{array}{c}-0.06 \\
0.19\end{array}$ & $\begin{array}{c}-0.04 \\
0.17\end{array}$ \\
\hline IE score on correct graphemes & $\begin{array}{c}\mathbf{0 . 0 4} \\
(0.02)\end{array}$ & $\begin{array}{l}0.01 \\
0.07\end{array}$ & $\begin{array}{l}0.02 \\
0.07\end{array}$ & $\begin{array}{r}-0.05 \\
(0.01)\end{array}$ & $\begin{array}{l}-0.07 \\
-0.02\end{array}$ & $\begin{array}{l}-0.07 \\
-0.03\end{array}$ & $\begin{array}{c}0.01 \\
(0.02)\end{array}$ & $\begin{array}{c}-0.03 \\
0.04\end{array}$ & $\begin{array}{c}-0.03 \\
0.03\end{array}$ \\
\hline IE score on alphabetical errors & $\begin{array}{c}0.01 \\
(0.17)\end{array}$ & $\begin{array}{c}-0.33 \\
0.33\end{array}$ & $\begin{array}{c}-0.27 \\
0.29\end{array}$ & $\begin{array}{c}0.18 \\
(0.16)\end{array}$ & $\begin{array}{c}-0.12 \\
0.49\end{array}$ & $\begin{array}{c}-0.08 \\
0.44\end{array}$ & $\begin{array}{r}-0.19 \\
(0.22)\end{array}$ & $\begin{array}{c}-0.59 \\
0.25\end{array}$ & $\begin{array}{r}-0.56 \\
0.15\end{array}$ \\
\hline IE score on orthographical errors & $\begin{array}{r}-0.27 \\
(0.12)\end{array}$ & $\begin{array}{l}-0.50 \\
-0.03\end{array}$ & $\begin{array}{l}-0.47 \\
-0.08\end{array}$ & $\begin{array}{c}\mathbf{0 . 4 8} \\
(0.13)\end{array}$ & $\begin{array}{l}0.21 \\
0.72\end{array}$ & $\begin{array}{l}0.27 \\
0.69\end{array}$ & $\begin{array}{r}-0.21 \\
(0.17)\end{array}$ & $\begin{array}{c}-0.52 \\
0.13\end{array}$ & $\begin{array}{r}-0.47 \\
0.08\end{array}$ \\
\hline \multicolumn{10}{|l|}{ MEANS } \\
\hline Correct words & $\begin{array}{r}-1.37 \\
(0.13)\end{array}$ & $\begin{array}{l}-1.62 \\
-1.11\end{array}$ & $\begin{array}{l}-1.59 \\
-1.17\end{array}$ & $\begin{array}{r}-\mathbf{0 . 1 8} \\
(0.08)\end{array}$ & $\begin{array}{l}-0.33 \\
-0.02\end{array}$ & $\begin{array}{l}-0.31 \\
-0.05\end{array}$ & $\begin{array}{c}1.55 \\
(0.19)\end{array}$ & $\begin{array}{l}1.18 \\
1.93\end{array}$ & $\begin{array}{l}1.25 \\
1.88\end{array}$ \\
\hline Correct graphemes & $\begin{array}{r}-1.34 \\
(0.04)\end{array}$ & $\begin{array}{l}-1.40 \\
-1.26\end{array}$ & $\begin{array}{l}-1.39 \\
-1.28\end{array}$ & $\begin{array}{r}-\mathbf{0 . 1 2} \\
(0.02)\end{array}$ & $\begin{array}{l}-0.16 \\
-0.07\end{array}$ & $\begin{array}{l}-0.16 \\
-0.08\end{array}$ & $\begin{array}{c}1.45 \\
(0.05)\end{array}$ & $\begin{array}{l}1.36 \\
1.55\end{array}$ & $\begin{array}{l}1.38 \\
1.54\end{array}$ \\
\hline Alphabetical errors & $\begin{array}{c}0.36 \\
(0.42)\end{array}$ & $\begin{array}{c}-0.51 \\
1.15\end{array}$ & $\begin{array}{c}-0.32 \\
1.08\end{array}$ & $\begin{array}{c}\mathbf{0 . 5 2} \\
(0.26)\end{array}$ & $\begin{array}{l}0.01 \\
1.04\end{array}$ & $\begin{array}{l}0.09 \\
0.94\end{array}$ & $\begin{array}{r}-0.88 \\
(0.61)\end{array}$ & $\begin{array}{c}-2.14 \\
0.32\end{array}$ & $\begin{array}{r}-1.93 \\
0.10\end{array}$ \\
\hline Orthographical errors & $\begin{array}{c}1.13 \\
(0.34)\end{array}$ & $\begin{array}{l}0.47 \\
1.83\end{array}$ & $\begin{array}{l}0.59 \\
1.73\end{array}$ & $\begin{array}{c}\mathbf{0 . 4 0} \\
(0.21)\end{array}$ & $\begin{array}{l}0.01 \\
0.80\end{array}$ & $\begin{array}{l}0.06 \\
0.74\end{array}$ & $\begin{array}{r}-1.52 \\
(0.51)\end{array}$ & $\begin{array}{l}-2.61 \\
-0.54\end{array}$ & $\begin{array}{r}-2.35 \\
-0.66\end{array}$ \\
\hline IE score & $\begin{array}{c}1.21 \\
(0.08)\end{array}$ & $\begin{array}{l}1.04 \\
1.36\end{array}$ & $\begin{array}{l}1.08 \\
1.35\end{array}$ & $\begin{array}{r}-\mathbf{0 . 1 4} \\
(0.06)\end{array}$ & $\begin{array}{l}-0.26 \\
-0.03\end{array}$ & $\begin{array}{l}-0.24 \\
-0.05\end{array}$ & $\begin{array}{r}-1.06 \\
(0.07)\end{array}$ & $\begin{array}{l}-1.20 \\
-0.94\end{array}$ & $\begin{array}{l}-1.17 \\
-0.96\end{array}$ \\
\hline
\end{tabular}

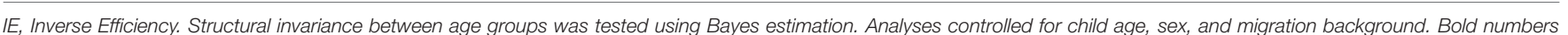

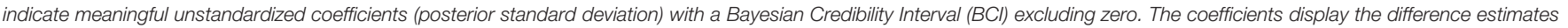
between the respective structural parameter and its average across the three age groups (i.e., difference value = group parameter-parameter average).

spelling strategy. Higher levels of the third graders' attention shifting skills were associated with more correctly written words and graphemes, and fewer orthographic errors. For the eighth graders, attention shifting was related to general spelling skills, with higher attention shifting skills being associated with more correctly written graphemes. The detailed model parameters (regression coefficients, posterior standard deviation, Bayesian credibility intervals) are reported in Table 3.

\section{The Role of Attention Shifting for Orthographic Competencies: Testing Sex Invariance within Each Grade Level}

To answer the second research question (i.e., Does attention shifting relate to orthographic competencies equally for boys and girls within each age group?), separate sets of models were run to test structural sex invariance within Grade 1, Grade 3, and Grade 8. For the first-grade students, the full invariant model across sex resulted in a DIC of 1164.21. The corresponding full non-invariant model revealed a DIC of 1137.34, showing a meaningful difference for the regression coefficient between attention shifting and general spelling skills for boys and girls (i.e., number of correct graphemes; Table 4). The partial invariant model releasing the corresponding parameter showed a DIC of 1138.13. Thus, the full non-invariant model was preferred. The model indicated a meaningful relation between attention shifting and general spelling skills indicating that higher attention shifting was associated with fewer correctly written words and graphemes
(Table 5 and Figure 2A). However, the relation was only found for the boys in Grade 1 but not for the girls.

For the third-grade group, compared to the full non-invariant model (DIC $=2087.60)$ the full invariant model across sex showed a lower DIC (DIC $=2079.98$ ). No meaningful differences were found in the difference tests of the full non-invariant model and, thus, the full invariant model was preferred (Table 4). Among third grade students of both sexes, attention shifting showed meaningful relations with general spelling skills (i.e., number of correctly written words and graphemes) and with students' proficiency in the use of specific spelling strategies (Table 6 and Figure 2B). Higher levels of attention shifting were related with higher general spelling skills and with less alphabetical and orthographic errors in students' writing sample.

With regard to the eighth-grade students, the full invariant model across sex yielded a DIC of 1931.79. The full non-invariant model showed a DIC of 1943.89. The full non-invariant model, however, indicated that the boys compared to the girls had higher word-level spelling skills (i.e., produced more correct words and graphemes in their writing sample) and made less caserelated errors. In addition, the regression coefficients of attention shifting on the number of correct graphemes differed for the boys and the girls. Therefore, a partial invariant model was run that released the respective parameters. The model showed the lowest DIC (1928.56) and was therefore considered the preferred model. In the partial invariance model, the girls' but not the boys' attention shifting was meaningfully related with the number 


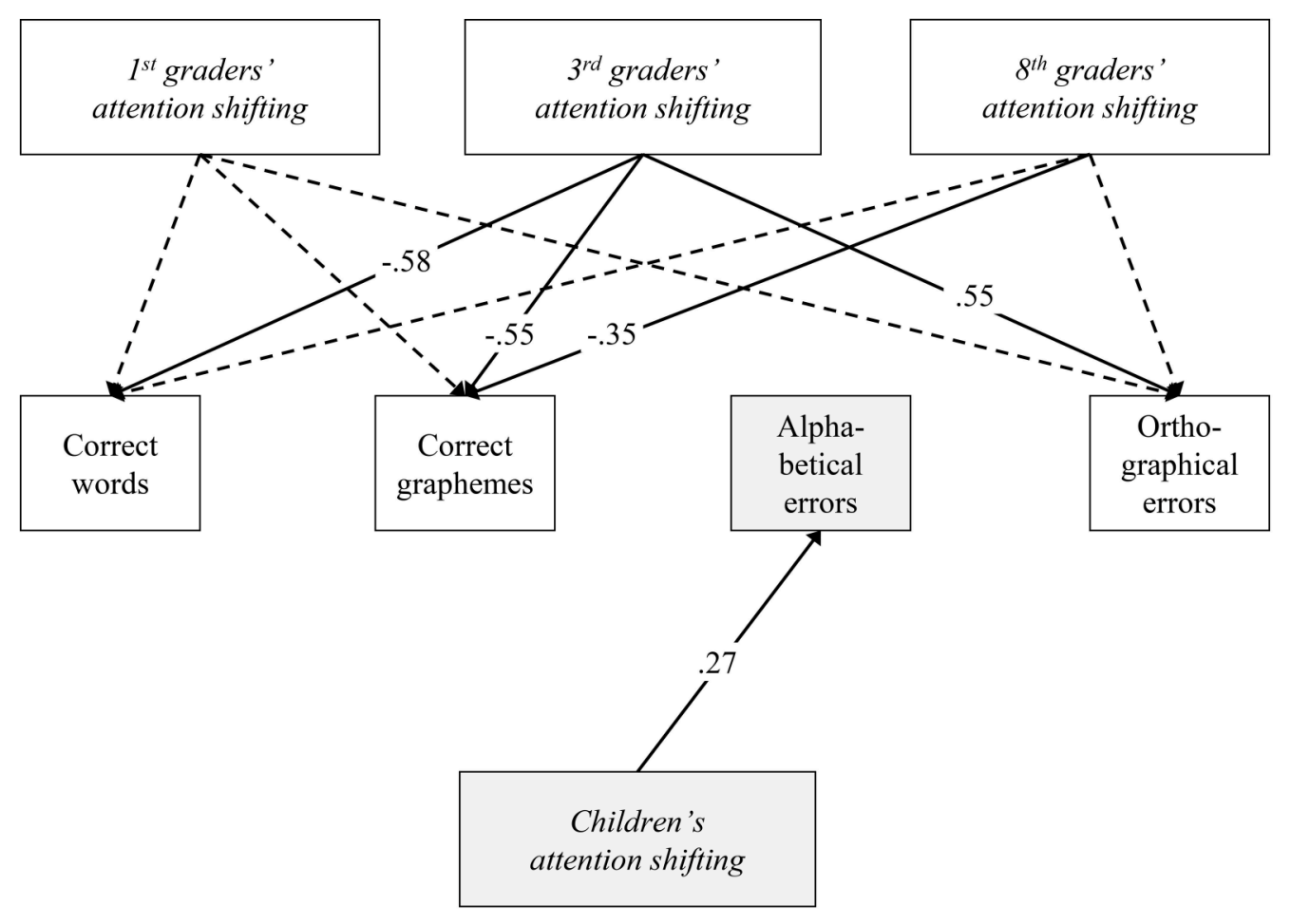

FIGURE 1 | Favored structural partial invariant model regarding age for prediction of orthographic competences. Structural age invariance was tested using Bayes estimation. Analyses control for child age, gender, and migration background. Solid lines indicate meaningful relations (standardized coefficients), each with a Bayesian Credibility Interval excluding zero (see Tables 2, 3). Gray boxes highlight age invariant relations.

of correct graphemes. Thus, among the eighth-grade students, higher attention shifting skills were related with higher general spelling skills at the level of the grapheme, but only for the girls. At the same time, a meaningful relation between attention shifting and case-related errors was found for both, the boys and girls (see Table 7 and Figure 2C). Higher attention shifting was related with higher proficiency in capitalization for both sexes.

\section{DISCUSSION}

The present study examined associations between attention shifting, word-level spelling skills and specific spelling strategies in a group of first, third, and eighth grade students. In general, attention shifting was related to spelling outcomes for all of the students. The associations were particularly strong among the third-grade students. In this age group, there were no sex differences in the relations between attention shifting and spelling outcomes. Among the first- and eighthgrade students, however, findings suggest sex differences in the relationship between attention shifting and general, i.e., word-level spelling. While for the eighth-grade girls, higher attention shifting skills were related to higher general spelling skills, the opposite was true for the first-grade boys, i.e., higher attention shifting skills were related to lower general spelling skills. Together, the findings add to the literature by suggesting that the pattern of associations between attention shifting and various orthographic competencies differs across age groups and by sex.

\section{Age-Related Similarities and Differences in the Pattern of Associations}

The current study expanded on previous research by providing initial evidence of age-related similarities and differences in the pattern of associations between attention shifting, one core component of executive functions, and spelling, that depended on whether general (i.e., word-level) spelling skills or specific spelling strategies were examined. One obvious hypothesis is that shifting abilities should be equally important for wordlevel spelling across different stages of spelling development. This is because word-level spelling requires shifting between several mental tasks, including "listening to the dictation, writing words either by retrieving their orthographic form from memory or by applying phoneme-grapheme correspondence rules [...], and verifying their production" (Lubin et al., 2016, p. 453) that should not differ between beginning and proficient spellers. In our study, attention shifting was related to general spelling among the third-grade and the eighth-grade students (though the associations among the eighth graders were only at the level of the grapheme). However, we did not find that attention shifting was related to general spelling skills among the first-grade students in comparison with the other age groups. 


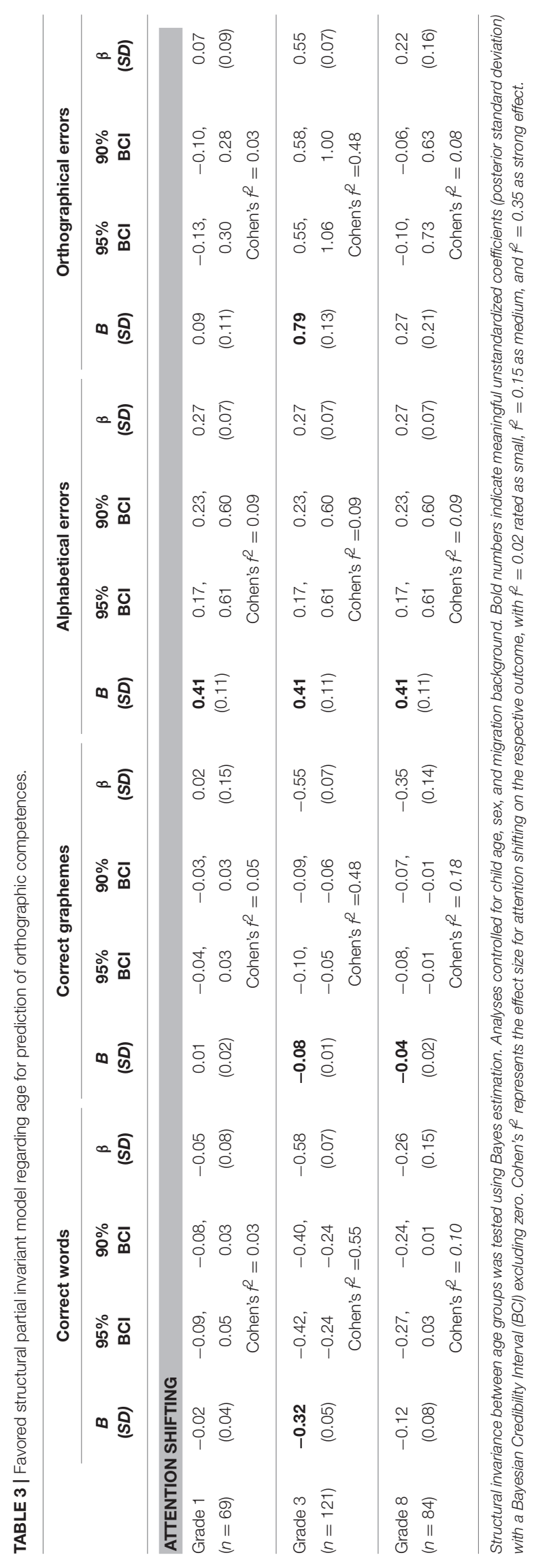

It could be that our findings may reflect specifics of spelling instruction in schools. In Germany, instructional emphasis in the early elementary grades is on phonemic spelling with teachers predominantly using words that have consistent one-to-one grapheme-phoneme-correspondence (Valtin, 1997). This results in a high probability of correct spelling. Thus, first graders' spelling might not draw heavily on attention shifting. The relative contribution of attention shifting to spelling, however, might change when students enter Grade 3 and are expected to apply spelling rules in order to master the spelling of unfamiliar words that contain inconsistencies between sound and orthographic patterns (Valtin, 1997; Moll et al., 2009). That is the time when individual differences in spelling become more prominent as students wrongly apply specific orthographic regularities where they are not needed (Valtin, 1997; Moll et al., 2009). Our findings suggest that attention shifting skills might provide a potential explanation for individual differences in spelling among older students. This assumption is supported by previous work reporting that shifting abilities but not working memory and inhibition accounted for variance in fourth graders' spelling skills (Lubin et al., 2016). Although, our study is among the first to investigate the relation between attention shifting and spelling outcomes at different stages of spelling acquisition, longitudinal research following children from middle childhood into adolescence is needed to better understand the (possibly changing) role that attention shifting plays in word-level spelling.

With regard to specific spelling strategies, attention shifting was related to the alphabetical strategy for all of the students across grades. That is, independent of the students' developmental level of spelling proficiency, faster but accurate performance on the DCCS was associated with less errors in applying the alphabetic principle to one's writing. A possible explanation could be that shifting abilities influence how spelling-relevant information is processed (Buchholz and Davies, 2005). For both beginning and proficient spellers, the ability to understand and apply the alphabetic principle has been linked to phonological processing (Dich and Cohn, 2013; Moll et al., 2014; Yeong et al., 2014). Deficits in attention were associated with impairments in phonological processing skills (Facoetti et al., 2010). Across different stages of spelling acquisition, shifting abilities may be important for the alphabetic spelling strategy because of the relationship with phonological processing skills. Future research should thus include this construct when studying associations between attention shifting and spelling skills.

An unexpected finding was that attention shifting was related to the orthographic strategy only among the third grade students. In the German orthography, most spelling errors are caused by orthographic deficits (Moll et al., 2009). That is, "phonemegrapheme conversion results in phonologically adequate but orthographically incorrect spellings" (Moll et al., 2009, p. 4). Consequently, attention shifting should be equally important for orthographic processing at all stages of spelling acquisition due to its importance for one's ability to differentiate between various representations of letter-sound correspondences. However, our findings could point to age-related changes in the association between attention shifting and orthographic spelling. Shifting abilities undergo rapid developmental changes from middle 
TABLE 4 | Results of difference test for structural sex invariance analyses of the full non-invariant models in grade 1, 3, and 8.

\begin{tabular}{|c|c|c|c|c|c|c|c|c|c|}
\hline & \multicolumn{3}{|c|}{ Grade $1(n=69)$} & \multicolumn{3}{|c|}{ Grade $3(n=121)$} & \multicolumn{3}{|c|}{ Grade $8(n=84)$} \\
\hline & $\begin{array}{c}B \\
(S D)\end{array}$ & $\begin{array}{c}95 \% \\
\text { BCI }\end{array}$ & $\begin{array}{c}90 \% \\
\mathrm{BCl}\end{array}$ & $\begin{array}{c}B \\
(S D)\end{array}$ & $\begin{array}{c}95 \% \\
\mathrm{BCl}\end{array}$ & $\begin{array}{c}90 \% \\
\mathrm{BCl}\end{array}$ & $\begin{array}{c}B \\
(S D)\end{array}$ & $\begin{array}{c}95 \% \\
\mathrm{BCl}\end{array}$ & $\begin{array}{c}90 \% \\
\mathrm{BCl}\end{array}$ \\
\hline \multicolumn{10}{|l|}{ REGRESSION COEFFICIENTS } \\
\hline IE score on correct words & $\begin{array}{r}-0.19 \\
(0.26)\end{array}$ & $\begin{array}{c}-0.79 \\
0.17\end{array}$ & $\begin{array}{c}-0.61 \\
0.17\end{array}$ & $\begin{array}{r}-0.29 \\
(0.20)\end{array}$ & $\begin{array}{c}-0.75 \\
0.09\end{array}$ & $\begin{array}{c}-0.60 \\
0.05\end{array}$ & $\begin{array}{r}-0.31 \\
(0.27)\end{array}$ & $\begin{array}{c}-0.85 \\
0.16\end{array}$ & $\begin{array}{r}-0.69 \\
0.14\end{array}$ \\
\hline IE score on correct graphemes & $\begin{array}{r}-\mathbf{0 . 3 7} \\
(0.20)\end{array}$ & $\begin{array}{l}-0.85 \\
-0.05\end{array}$ & $\begin{array}{l}-0.69 \\
-0.05\end{array}$ & $\begin{array}{r}-0.26 \\
(0.20)\end{array}$ & $\begin{array}{c}-0.65 \\
0.14\end{array}$ & $\begin{array}{c}-0.58 \\
0.09\end{array}$ & $\begin{array}{r}-\mathbf{0 . 3 9} \\
(0.25)\end{array}$ & $\begin{array}{c}-0.83 \\
0.10\end{array}$ & $\begin{array}{l}-0.83 \\
-0.05\end{array}$ \\
\hline IE score on alphabetical errors & $\begin{array}{r}-0.15 \\
(0.28)\end{array}$ & $\begin{array}{c}-0.65 \\
0.41\end{array}$ & $\begin{array}{c}-0.55 \\
0.35\end{array}$ & $\begin{array}{c}0.08 \\
(0.20)\end{array}$ & $\begin{array}{c}-0.30 \\
0.49\end{array}$ & $\begin{array}{c}-0.24 \\
0.42\end{array}$ & $\begin{array}{c}0.19 \\
(0.30)\end{array}$ & $\begin{array}{c}-0.38 \\
0.69\end{array}$ & $\begin{array}{c}-0.38 \\
0.58\end{array}$ \\
\hline IE score on orthographical errors & $\begin{array}{r}-0.26 \\
(0.24)\end{array}$ & $\begin{array}{c}-0.68 \\
0.19\end{array}$ & $\begin{array}{c}-0.61 \\
0.15\end{array}$ & $\begin{array}{c}0.22 \\
(0.20)\end{array}$ & $\begin{array}{c}-0.20 \\
0.61\end{array}$ & $\begin{array}{c}-0.12 \\
0.56\end{array}$ & $\begin{array}{c}0.27 \\
(0.30)\end{array}$ & $\begin{array}{c}-0.36 \\
0.79\end{array}$ & $\begin{array}{c}-0.18 \\
0.79\end{array}$ \\
\hline IE score on morphological errors & - & - & - & - & - & - & $\begin{array}{c}0.25 \\
(0.21)\end{array}$ & $\begin{array}{c}-0.11 \\
0.66\end{array}$ & $\begin{array}{c}-0.11 \\
0.58\end{array}$ \\
\hline IE score on redundant elements & $\begin{array}{r}-0.21 \\
(0.18)\end{array}$ & $\begin{array}{c}-0.50 \\
0.20\end{array}$ & $\begin{array}{c}-0.49 \\
0.09\end{array}$ & $\begin{array}{c}0.39 \\
(0.42)\end{array}$ & $\begin{array}{c}-0.41 \\
1.23\end{array}$ & $\begin{array}{c}-0.35 \\
1.04\end{array}$ & - & - & - \\
\hline IE score on case-related errors & - & - & - & - & - & - & $\begin{array}{r}-0.10 \\
(0.51)\end{array}$ & $\begin{array}{c}-1.03 \\
0.98\end{array}$ & $\begin{array}{r}-0.73 \\
0.93\end{array}$ \\
\hline \multicolumn{10}{|l|}{ MEANS } \\
\hline Correct words & $\begin{array}{r}-0.29 \\
(0.27)\end{array}$ & $\begin{array}{c}-0.88 \\
0.12\end{array}$ & $\begin{array}{c}-0.73 \\
0.12\end{array}$ & $\begin{array}{r}-0.05 \\
(0.19)\end{array}$ & $\begin{array}{c}-0.44 \\
0.31\end{array}$ & $\begin{array}{c}-0.36 \\
0.27\end{array}$ & $\begin{array}{r}-\mathbf{0 . 4 7} \\
(0.23)\end{array}$ & $\begin{array}{l}-0.90 \\
-0.04\end{array}$ & $\begin{array}{l}-0.81 \\
-0.08\end{array}$ \\
\hline Correct graphemes & $\begin{array}{r}-0.09 \\
(0.24)\end{array}$ & $\begin{array}{c}-0.60 \\
0.33\end{array}$ & $\begin{array}{c}-0.51 \\
0.26\end{array}$ & $\begin{array}{r}-0.15 \\
(0.19)\end{array}$ & $\begin{array}{c}-0.52 \\
0.24\end{array}$ & $\begin{array}{c}-0.45 \\
0.18\end{array}$ & $\begin{array}{r}-\mathbf{0 . 4 6} \\
(0.23)\end{array}$ & $\begin{array}{c}-0.88 \\
0.05\end{array}$ & $\begin{array}{l}-0.88 \\
-0.12\end{array}$ \\
\hline Alphabetical errors & $\begin{array}{c}0.12 \\
(0.30)\end{array}$ & $\begin{array}{c}-0.52 \\
0.71\end{array}$ & $\begin{array}{c}-0.43 \\
0.51\end{array}$ & $\begin{array}{r}-0.25 \\
(0.20)\end{array}$ & $\begin{array}{c}-0.64 \\
0.15\end{array}$ & $\begin{array}{c}-0.56 \\
0.10\end{array}$ & $\begin{array}{c}0.28 \\
(0.25)\end{array}$ & $\begin{array}{c}-0.22 \\
0.71\end{array}$ & $\begin{array}{c}-0.09 \\
0.71\end{array}$ \\
\hline Orthographical errors & $\begin{array}{c}0.12 \\
(0.29)\end{array}$ & $\begin{array}{c}-0.44 \\
0.68\end{array}$ & $\begin{array}{c}-0.30 \\
0.63\end{array}$ & $\begin{array}{c}0.08 \\
(0.20)\end{array}$ & $\begin{array}{c}-0.26 \\
0.51\end{array}$ & $\begin{array}{c}-0.24 \\
0.39\end{array}$ & $\begin{array}{c}0.06 \\
(0.23)\end{array}$ & $\begin{array}{c}-0.37 \\
0.47\end{array}$ & $\begin{array}{c}-0.33 \\
0.39\end{array}$ \\
\hline Morphological errors & - & - & - & - & - & - & $\begin{array}{r}-0.01 \\
(0.22)\end{array}$ & $\begin{array}{c}-0.41 \\
0.41\end{array}$ & $\begin{array}{c}-0.38 \\
0.28\end{array}$ \\
\hline Redundant elements & $\begin{array}{r}-0.25 \\
(0.19)\end{array}$ & $\begin{array}{c}-0.66 \\
0.10\end{array}$ & $\begin{array}{c}-0.52 \\
0.10\end{array}$ & $\begin{array}{r}-0.09 \\
(0.40)\end{array}$ & $\begin{array}{c}-0.85 \\
0.73\end{array}$ & $\begin{array}{c}-0.70 \\
0.62\end{array}$ & - & - & - \\
\hline Case-related errors & - & - & - & - & - & - & $\begin{array}{c}1.40 \\
(0.47)\end{array}$ & $\begin{array}{l}0.42 \\
2.29\end{array}$ & $\begin{array}{l}0.60 \\
2.13\end{array}$ \\
\hline IE score & $\begin{array}{c}0.20 \\
(0.50)\end{array}$ & $\begin{array}{c}-0.73 \\
1.29\end{array}$ & $\begin{array}{r}-0.55 \\
1.04\end{array}$ & $\begin{array}{c}0.30 \\
(0.20)\end{array}$ & $\begin{array}{c}-0.08 \\
0.70\end{array}$ & $\begin{array}{c}-0.03 \\
0.63\end{array}$ & $\begin{array}{c}0.01 \\
(0.25)\end{array}$ & $\begin{array}{c}-0.51 \\
0.42\end{array}$ & $\begin{array}{r}-0.43 \\
0.37\end{array}$ \\
\hline
\end{tabular}

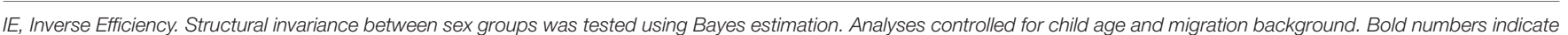

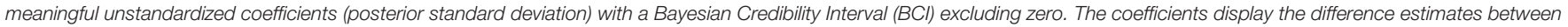
girls' and boys' respective parameters (i.e., difference value = girls' parameter - boys' parameter).

childhood to early adolescence (Anderson, 2010). During the same period, children learn to apply orthographic knowledge to their spelling (e.g., Cunningham et al., 2002; SprengerCharolles et al., 2003; Roman et al., 2009; Yeong et al., 2014). Shifting abilities may be particularly relevant for orthographic skills during the initial phase of building up proficiency in orthographic processing and less relevant later in development. As discussed above, from the beginning of Grade 3 students are increasingly exposed to inconsistencies of the German spelling system while they still lack adequate orthographic knowledge to cope with these inconsistencies (Moll et al., 2009). One possible explanation for our finding is that at this stage of spelling acquisition students with low attention shifting may have difficulties in building up orthographic proficiency. However, the directionality of the examined associations could not fully be identified due to the cross-sectional nature of the data. Alternatively, attention shifting may be indirectly related to orthographic skills through word-specific knowledge. Moll and colleagues (Moll et al., 2009, 2014) argue that the capacity of one's orthographic lexicon is an important predictor of orthographically correct spellings. Attention shifting may be relevant for more specific mechanisms underlying orthographic spelling. For example, correct spelling requires recall activity that is related to shifting abilities because students need to switch between different levels of analyzing words (Aram et al., 2014; Lubin et al., 2016). Further research is needed to investigate the mechanisms that may explain age-related differences in the relation between attention shifting and specific spelling strategies.

\section{Sex Differences in the Associations between Attention Shifting and Spelling Outcomes}

We found that the relation between attention shifting and general (i.e., word-level) spelling skills differed for boys and girls but only among first and eighth graders. In contrast, no sex differences were found in the association between attention shifting and specific spelling strategies. Among first-grade boys only, slower 


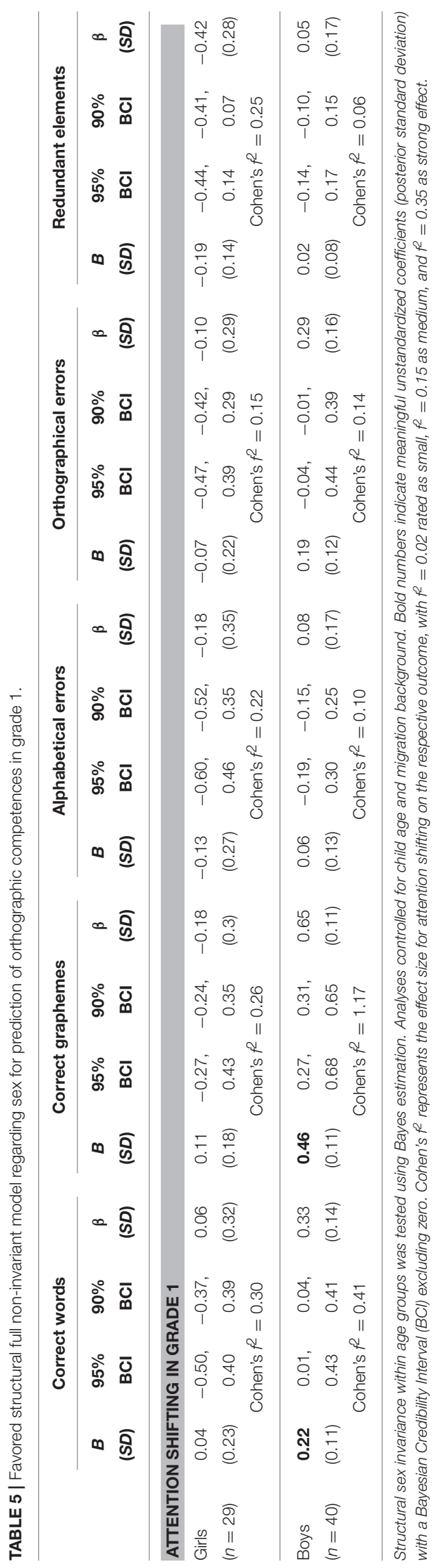

and less accurate performance on the DCCS was associated with higher spelling skills at the word level (i.e., more correctly written words and graphemes). Our data does not explain why this was the case. Children with lower shifting abilities may benefit from the emphasis on words with consistent oneto-one grapheme-phoneme-correspondence which might not draw heavily on attention shifting. The emphasis on one-toone grapheme-phoneme-correspondence is typical of spelling instruction in the early elementary years in Germany (Valtin, 1997). The boys with lower shifting abilities in our first-grade group could thus still be able to produce correct spellings because errors in the words' phoneme-grapheme conversion are less likely. In the eighth-grade sample, higher attention shifting skills were related to the girls' (but not boys') higher general spelling skills. These findings speak to the well documented achievement advantage for girls in secondary school (Bos et al., 2007; Quenzel and Hurrelmann, 2010).

The present findings could reflect sex differences in the strategies that boys and girls apply when directing their attention (Sobeh and Spijkers, 2012, 2013). There is initial evidence that boys perform faster in attention shifting tasks whereas girls demonstrate better accuracy (Sobeh and Spijkers, 2012, 2013). Influenced by biological factors, "accuracy of performance seems to develop earlier than the speed of performance" (Sobeh and Spijkers, 2013, p. 332). Sex differences in developmental trajectories of attention strategies may give girls an advantage to apply their shifting skills in a way that benefits their spelling, whereas for boys this might not be the case. It may even adversely affect their spelling, in particular, during the early elementary years. However, more research is needed to disentangle possible age-related changes in the mechanisms underlying sex differences in attention shifting and its relations to achievement outcomes, such as spelling.

An alternative explanation for the detected sex differences in the associations could be a measurement artifact. In the present study, spelling was measured using a conventional paper-andpencil spelling test. Results of a study that compared spelling performance on paper-and-pencil tests and computerized tests suggest that boys perform better on computerized tests (Horne, 2007). Horne (2007) argued that using a computer enhances boys' motivation to engage with the test which results in more accurate performance. In addition, the sex differences could be due to differences in children's hand writing abilities which could not be tested in this study. Thus, our spelling measure may have underestimated boys' spelling level which might have resulted in the negative relation between attention shifting and spelling for the first graders.

\section{Practical Implications}

The present results have several implications for educational practice. First, students' spelling proficiency may be improved by enhancing teachers' awareness of the importance of attention shifting for spelling skills. Several studies have shown that teachers' pedagogical knowledge influences classroom practices and the quality of instruction which in turn has an effect on students' learning and performance (e.g., Metzler and Woessmann, 2012; Kunter et al., 2013; König and Pflanzl, 

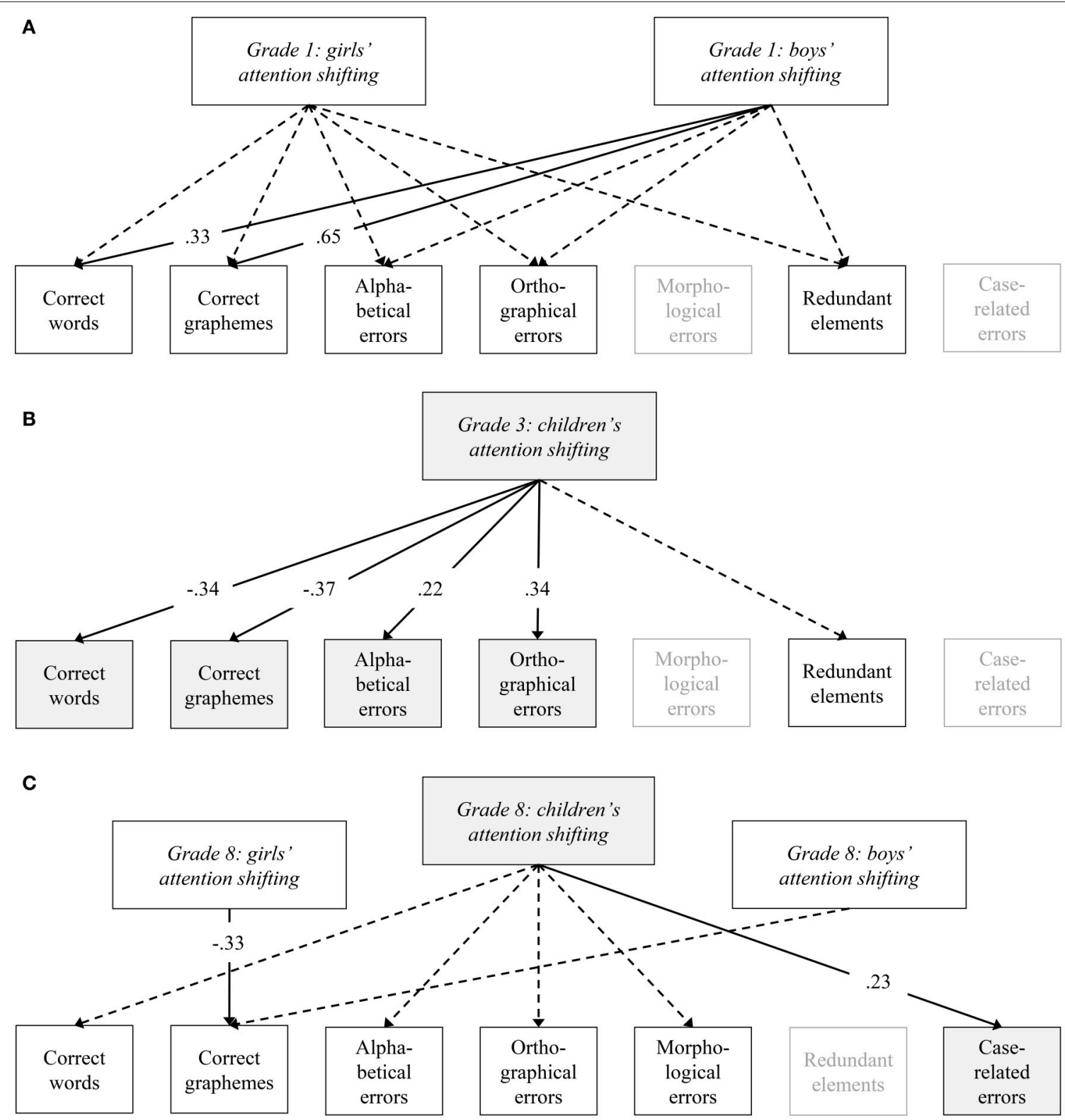

FIGURE 2 | (A) Favored structural full non-invariant model regarding gender for prediction of orthographic competences in grade 1. (B) Favored structural full invariant model regarding gender for prediction of orthographic competences in grade 3. (C) Favored structural partial invariant model regarding gender for prediction of orthographic competences in grade 8. (A-C) Structural gender invariance was tested using Bayes estimation. Analyses control for child age, gender, and migration background. Solid lines indicate meaningful relations (standardized coefficients), each with a Bayesian Credibility Interval excluding zero (see Tables 1-4). Gray boxes highlight gender invariant relations.

2016). Second, efforts to improve students' spelling might benefit from a focus on attention shifting. Intervention studies of school-based programs reported improvements in students' executive functions with particular strong effects on children with executive function difficulties (e.g., Diamond et al., 2007; Flook et al., 2010; Diamond and Lee, 2011). Positive effects of reading-specific flexibility exercises (focusing on shifting attention between phonological and semantic dimensions) that were completed with students as part of regular classroom activities have been shown to improve elementary students' reading (Cartwright, 2006). Such programs might be particularly relevant for third grade students who have to master the transition from phonological to orthographic spelling. Thus, providing a learning environment with ample opportunities to learn and practice executive function skills may facilitate students' spelling acquisition. Finally, many educational tests use general (i.e., word-level) spelling scores to classify students into good and poor spellers. As a consequence, spelling instruction 


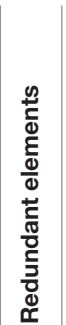

亏े

-

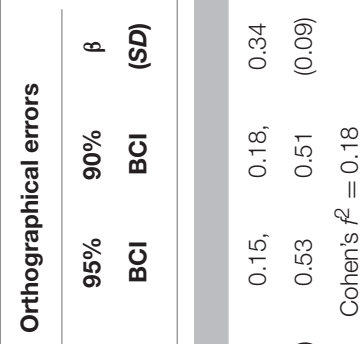

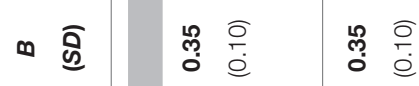

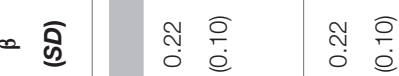

畜 $\overline{0}$

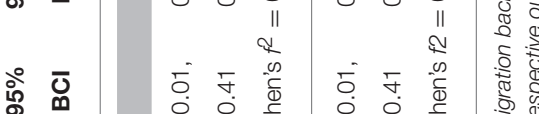

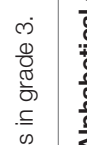

边

$\infty$

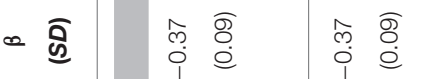

高 $\overline{0}$

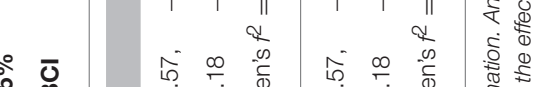

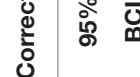

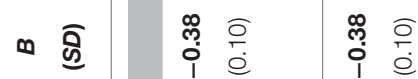

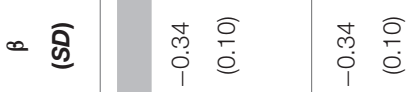

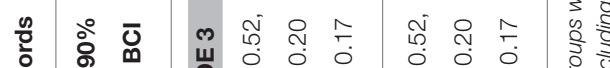

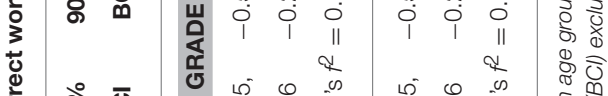
ठ̀.

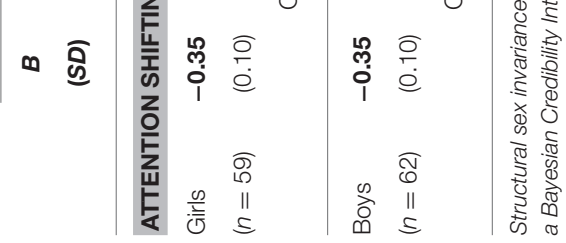

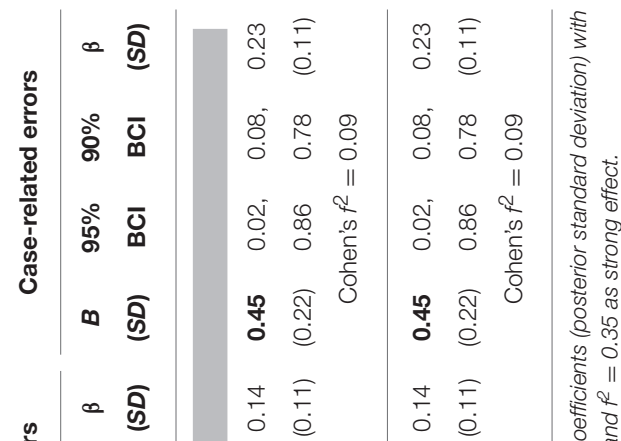

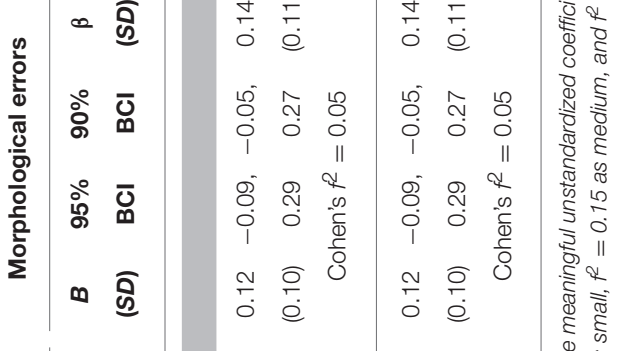

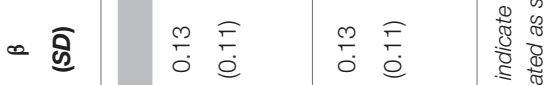

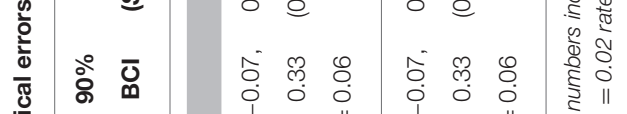

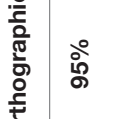

(

$\infty$ 勾

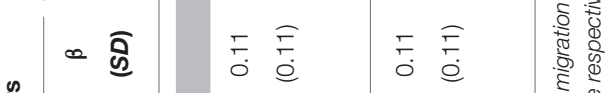

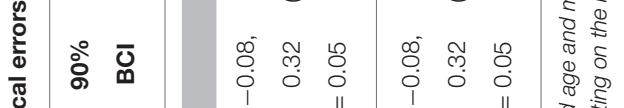

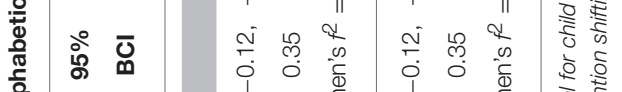

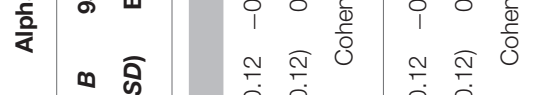

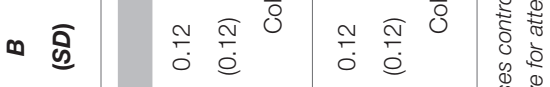

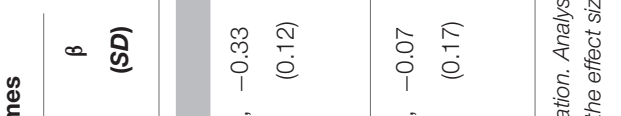

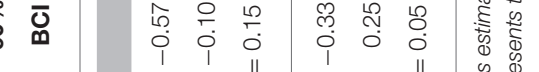

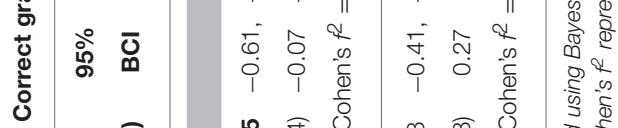

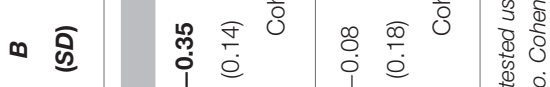

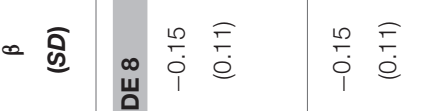

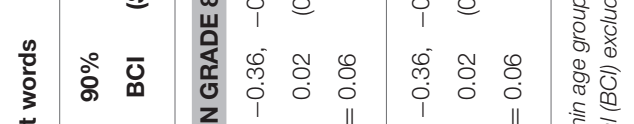

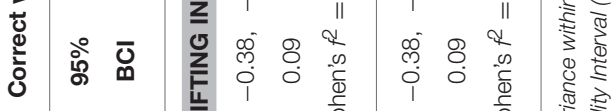

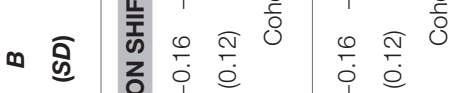

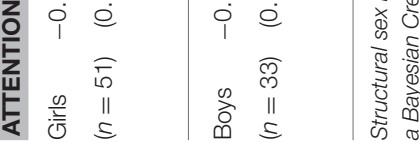


has centered around the spelling of words. However, students might benefit from a focus on various specific spelling strategies after they have acquired foundational knowledge of letter-sound correspondences (Keunig and Verhoeven, 2008).

\section{Limitations and Future Directions}

Although, our study addresses several limitations of prior work by including a wide age range and using age-appropriate versions of the same tasks to measure attention shifting and spelling outcomes, some caveats should be noted when interpreting the results. Our results suggested age-related differences in the associations between attention shifting and spelling outcomes. Unobserved variables such as intelligence and socioeconomic status may have accounted for the associations between attention shifting and spelling outcomes. Limitations in the available data did not allow us to control for these variables in the present analyses. However, previous research suggests that executive functions predict academic outcomes above and beyond intelligence (Duckworth and Seligman, 2005; Lubin et al., 2016) and socioeconomic status (Moffitt et al., 2011).

A second limitation is that the cross-sectional design of our study did not allow us to follow individual students over time. Thus, the differences between age groups may be due to student characteristics specific to each age group that could not be controlled in the present analyses. Future research should use a longitudinal design to investigate developmental trajectories of the relation between attention shifting and spelling which could also give insights into possible bidirectional associations of these two developing skills from childhood to adolescence. There is emerging evidence of simultaneous growth and reciprocal relations between executive functions and literacy skills during the early childhood years (Bohlmann et al., 2015; Slot and von Suchodoletz, submitted), but research from middle childhood into adolescence is still scarce.

Additional limitations concern the small sample sizes for each age group, in particular, when analyzing sex differences within each sample. Further studies are needed to confirm the findings with a larger sample. Another limiting fact refers to the missing analogy in covered characteristics between the measures used to assess spelling and attention shifting. While the latter was assessed with a process-related measure (inverse efficiency score produced by percentage of correct trials and their reaction times of the DCCS), we had no information on, for example,

\section{REFERENCES}

Anderson, P. (2010). Assessment and development of executive function (EF) during childhood. Child Neuropsychol. 8, 71-82. doi: 10.1076/chin.8.2. 71.8724

Aram, D., Abiri, S., and Elad, L. (2014). Predicting early spelling: the contribution of children's early literacy, private speech during spelling, behavioral regulation, and parental spelling support. Read. Writ. 27, 685-707. doi: 10.1007/s11145-013-9466-Z

Berninger, V. W., and Fuller, F. (1992). Gender differences in orthographic, verbal, and compositional fluency: implications for assessing writing disabilities in primary grade children. J. Sch. Psychol. 30, 363-382. doi: 10.1016/0022-4405(92)90004-O writing speed and error handling during the process of writing. A better congruence between measures should be a focus in future research. Finally, to get a more accurate picture of the relative contribution of attention shifting to academic outcomes, it would be beneficial to include other core executive functions (e.g., working memory and inhibition) as well as further outcome variables (e.g., reading skills).

\section{CONCLUSION}

Together with previous research, the present cross-sectional findings emphasize the important role of attention shifting, one core component of executive functions, for German students' spelling skills in middle childhood and early adolescence. Efforts aimed at improving shifting abilities may help students to reach grade-level spelling proficiency. The findings are relevant for teacher education and professional development as they emphasize the necessity to enable teachers to tailor instructions to both reinforcing students' academic skills and their executive functions in order to improve school achievement. Finally, the study goes beyond previous research by providing an ageand sex-specific approach to the relation between attention shifting and spelling. Similarities and differences in the pattern of associations were identified that depend on students' age, sex, and specific spelling skill measured, thus, identifying possible developmental processes that should be examined by future research.

\section{AUTHOR CONTRIBUTIONS}

AvS conceptualized and designed the study. The data collection was conducted by AvS and IS. AF performed the statistical analyses. AvS and AF composed the paper. IS contributed to the writing of the manuscript.

\section{FUNDING}

The research reported here was supported by Grant SU 696/11 from the German Research Foundation (DFG) to AvS and by grants given to the Research Group "The Empirics of Education: Economic and Behavioral Perspectives" in the context of the German Initiative of Excellence at the University of Freiburg, Germany. 
Bierman, K. L., Nix, R. L., Greenberg, M. T., Blair, C., and Domitrovich, C. E. (2008). Executive functions and school readiness intervention: impact, moderation, and mediation in the Head Start REDI program. Dev. Psychopathol. 20, 821-843. doi: 10.1017/S0954579408000394

Blair, C., and Raver, C. C. (2015). School readiness and self-regulation: a developmental psychobiological approach. Annu. Rev. Psychol. 66, 711-736. doi: 10.1146/annurev-psych-010814-015221

Blair, C., and Razza, R. P. (2007). Relating effortful control, executive function, and false belief understanding to emerging math and literacy ability in kindergarten. Child Dev. 78, 647-663. doi: 10.1111/j.1467-8624.2007.01019.x

Blankson, A. N., and Blair, C. (2016). Cognition and classroom quality as predictors of math achievement in the kindergarten year. Learn. Instruct. 41, 32-40. doi: 10.1016/j.learninstruc.2015.09.004

Bohlmann, N. L., Maier, M. F., and Palacios, N. (2015). Bidirectionality in self-regulation and expressive vocabulary: comparisons between monolingual and dual language learners in preschool. Child Dev. 86, 1094-1111. doi: $10.1111 /$ cdev.12375

Bos, W., Hornberg, S., Arnold, K.-H., Faust, G., Fried, L., Lankes, E.M., et al. (2007). IGLU 2006. Lesekompetenzen von Grundschulkindern in Deutschland im internationalen Vergleich [IGLU 2006. Reading Competencies of Elementary School Children in Germany: An International Comparison]. Münster: Waxmann.

Buchholz, J., and Davies, A. A. (2005). Adults with dyslexia demonstrate spacebased and object-based covert attention deficits: shifting attention to the periphery and shifting attention between objects in the left visual field. Brain Cogn. 57, 30-34. doi: 10.1016/j.bandc.2004.08.017

Cartwright, K. B. (2006). Fostering flexibility and comprehension in elementary students. Read. Teach. 59, 628-634. doi: 10.1598/RT.59.7.2

Cassar, M. T., and Treiman, R. (1997). The beginnings of orthographic knowledge: children's knowledge of double letters in words. J. Educ. Psychol. 89, 631-644. doi: 10.1037/0022-0663.89.4.631

Christie, F., and Derewianka, B. (2010). School Discourse: Learning to Write Across the Years of Schooling. London: Continuum International Publishing Group.

Cuevas, K., Deater-Deckard, K., Kim-Spoon, J., Wang, Z., Morasch, K. C., and Bell, M. A. (2014). A longitudinal intergenerational analysis of executive functions during childhood. Br. J. Dev. Psychol. 32, 50-64. doi: 10.1111/bjdp.12021

Cunningham, A. E., Perry, K. E., Stanovich, K. E., and Share, D. L. (2002). Orthographic learning during reading. J. Exp. Child Psychol. 82, 185-199. doi: 10.1016/S0022-0965(02)00008-5

Diamond, A., Barnett, W. S., Thomas, J., and Munro, S. (2007). The early years: preschool program improves cognitive control. Science 318, 1387-1388. doi: $10.1126 /$ science. 1151148

Diamond, A., Carlson, S. M., and Beck, D. M. (2005). Preschool children's performance in task switching on the dimensional change card sort task: separating the dimensions aids the ability to switch. Dev. Neuropsychol. 28, 689-729. doi: 10.1207/s15326942dn2802_7

Diamond, A., and Kirkham, N. Z. (2005). Not quite as grown-up as we like to think: parallels between cognition in childhood and adulthood. Psychol. Sci. 16, 291-297. doi: 10.1111/j.0956-7976.2005.01530.x

Diamond, A., and Lee, K. (2011). Intervention shown to aid executive function development in children 4 to 12 years old. Science 333, 959-964. doi: 10.1126/science.1204529

Dich, N., and Cohn, A. C. (2013). A review of spelling acquisition: spelling development as a source of evidence for the psychological reality of the phoneme. Lingua 133, 213-229. doi: 10.1016/j.lingua.2013.04.010

Ding, X. P., Omrin, D. S., Evans, A. D., Fu, G., Chen, G., and Lee, K. (2014). Elementary school children's cheating behavior and its cognitive correlates. J. Exp. Child Psychol. 121, 85-95. doi: 10.1016/j.jecp.2013.12.005

DiPrete, T. A., and Jennings, J. L. (2012). Social and behavioral skills and the gender gap in early educational achievement. Soc. Sci. Res. 41, 1-15. doi: 10.1016/j.ssresearch.2011.09.001

Duckworth, A. L., and Seligman, M. E. P. (2005). Self-discipline outdoes IQ in predicting academic performance of adolescents. Psychol. Sci. 16, 939-944. doi: 10.1111/j.1467-9280.2005.01641.x

Else-Quest, N. M., Hyde, J. S., Goldsmith, H. H., and Van Hulle, C. A. (2006). Gender differences in temperament: a meta-analysis. Psychol. Bull. 132, 33-72. doi: 10.1037/0033-2909.132.1.33
Facoetti, A., Trussardi, A. N., Ruffino, M., Lorusso, M. L., Cattaneo, C., Galli, R., et al. (2010). Multisensory spatial attention deficits are predictive of phonological decoding skills in developmental dyslexia. J. Cogn. Neurosci. 22, 1011-1025. doi: 10.1162/jocn.2009.21232

Feng, Q., Zheng, Y., Zhang, X., Song, Y., Luo, Y., Li, Y., et al. (2011). Gender differences in visual reflexive attention shifting: evidence from an ERP study. Brain Res. 1401, 59-65. doi: 10.1016/j.brainres.2011. 05.041

Flook, L., Smalley, S. L., Kitil, J. M., Galla, B. M., Kaiser-Greenland, S., Locke, J., et al. (2010). Effects of mindfulness awareness practices on executive functions in elementary school children. J. Appl. School Psychol. 26, 70-95. doi: 10.1080/15377900903379125

Frith, U. (1985). "Beneath the surface of developmental dyslexia," in Surface Dyslexia: Neuropsychological and Cognitive Studies of Phonological Reading, eds K. E. J. C. Marshall and M. Colthart (London: Erlbaum), 301-330.

Gelman, A., Carlin, J. B., Stern, H. S., and Rubin, D. B. (2004). Bayesian Data Analysis, Second Edition. Boca Raton, FL: Chapman \& Hall.

Gestsdottir, S., von Suchodoletz, A., Wanless, S. B., Hubert, B., Guimard, P., Birgisdottir, F., et al. (2014). Early behavioral self-regulation, academic achievement, and gender: longitudinal findings from Germany, France, and Iceland. Appl. Dev. Sci. 18, 90-109. doi: 10.1080/10888691.2014.894870

Gunzenhauser, C., and von Suchodoletz, A. (2015). Boys might catch up, family influences continue: influences on behavioral self-regulation in children from an affluent region in Germany before school entry. Early Educ. Dev. 26, 645-662. doi: 10.1080/10409289.2015.1012188

Holmes, N. P., Calvert, G. A., and Spence, C. (2007). Tool use changes multisensory interactions in seconds: evidence from the crossmodal congruency task. Exp. Brain Res. 183, 465-476. doi: 10.1007/s00221-007-1060-7

Horne, J. (2007). Gender differences in computerised and conventional educational tests. J. Comput. Assist. Learn. 23, 47-55. doi: 10.1111/j.1365-2729.2007.00198.x

Keunig, J., and Verhoeven, L. (2008). Spelling development throughout the elementary grades: the Dutch case. Learn. Individ. Differ. 18, 459-470. doi: 10.1016/j.lindif.2007.12.001

Kitagawa, N., and Spence, C. (2005). Investigating the effect of a transparent barrier on the crossmodal congruency effect. Exp. Brain Res. 161, 62-71. doi: 10.1007/s00221-004-2046-3

Klenberg, L., Korkman, M., and Lahti-Nuuttila, P. (2001). Differential development of attention and executive functions in 3- to 12-year-old Finnish children. Dev. Neuropsychol. 20, 407-428. doi: 10.1207/S15326942DN2001_6

König, J., and Pflanzl, B. (2016). Is teacher knowledge associated with performance? On the relationship between teachers' general pedagogical knowledge and instructional quality. Eur. J. Teach. Educ. 39, 419-436. doi: 10.1080/02619768.2016.1214128

Kruschke, J. K. (2011). Bayesian assessment of null values via parameter estimation and model comparison. Perspect. Psychol. Sci. 6, 299-312. doi: $10.1177 / 1745691611406925$

Kunter, M., Klusmann, U., Baumert, J., Richter, D., Voss, T., and Hachfeld, A. (2013). Professional competence of teachers: effects on instructional quality and student development. J. Educ. Psychol. 105, 805-820. doi: 10.1037/a0032583

Lee, S., and Song, X. (2004). Evaluation of the Bayesian and maximum likelihood approaches in analyzing structural equation models with small sample sizes. Multivariate Behav. Res. 39, 653-686. doi: 10.1207/s15327906mbr3904_4

Levin, I., and Bus, A. (2003). How is emergent writing based on drawing? Analyses of children's products and their sorting by children and mothers. Dev. Psychol. 39, 891-905. doi: 10.1037/0012-1649.39.5.891

Lubin, A., Regrin, E., Boulc'h, L., Pacton, S., and Lanoë, C. (2016). Executive functions differentially contribute to fourth graders' mathematics, reading, and spelling skills. J. Cogn. Educ. Psychol. 15, 444-463. doi: 10.1891/1945-8959.15.3.444

Manly, T., Robertson, I. H., Anderson, V., and Nimmo-Smith, I. (1999). The Test of Everyday Attention for Children (TEA-CH). Bury St. Edmunds: Thames Valley Test.

Matthews, J. M., Cameron Ponitz, C., and Morrison, F. J. (2009). Early gender differences in self-regulation and academic achievement. J. Educ. Psychol. 101, 689-704. doi: 10.1037/a0014240 
May, P. (2002). Hamburger Schreib-Probe (HSP) [Hamburg Writing Test]. Hamburg: Verlag für pädagogische Medien.

McBride-Chang, C. (2004). Children's Literacy Development. New York, NY: Routledge.

McGeown, S. P., Medford, E., and Moxon, G. (2013). Individual differences in children's reading and spelling strategies and the skills supporting strategy use. Learn. Individ. Differ. 28, 75-81. doi: 10.1016/j.lindif.2013.09.013

Metzler, J., and Woessmann, L. (2012). The impact of teacher subject knowledge on student achievement: evidence from within-teacher within-student variation. J. Dev. Econ. 99, 486-496. doi: 10.1016/j.jdeveco.2012.06.002

Miyake, A., Friedman, N. P., Emerson, M. J., Witzki, A. H., Howerter, A., and Wager, T. D. (2000). The unity and diversity of executive functions and their contributions to complex "frontal lobe" tasks: a latent variable analysis. Cogn. Psychol. 41, 49-100. doi: 10.1006/cogp.1999.0734

Moffitt, T. E., Arseneault, L., Belsky, D., Dickson, N., Hancox, R. J., Harrington, H., et al. (2011). A gradient of childhood self-control predicts health, wealth, and public safety. Proc. Natl. Acad. Sci. U.S.A. 108, 2693-2698. doi: 10.1073/pnas. 1010076108

Moll, K., Fussenegger, B., Willburger, E., and Landerl, K. (2009). RAN is not a measure of orthographic processing. Evidence from the asymmetric German orthography. Sci. Stud. Read. 13, 1-25. doi: 10.1080/10888430802631684

Moll, K., Ramus, F., Bartling, J., Bruder, J., Kunze, S., Neuhoff, N., et al. (2014). Cognitive mechanisms underlying reading and spelling development in five European orthographies. Learn. Instruct. 29, 65-77. doi: 10.1016/j.learninstruc.2013.09.003

Monette, S., Bigras, M., and Guay, M.-C. (2011). The role of the executive functions in school achievement at the end of Grade 1. J. Exp. Child Psychol. 109, 158-173. doi: 10.1016/j.jecp.2011.01.008

Muthén, B. O. (2010, May 17). Bayesian Analysis in Mplus: A Brief Introduction. Incomplete Draft, Version 3. Available online at: http://www.statmodel.com/ download/IntroBayesVersion\%203.pdf (Accessed December 1, 2014).

Muthén, B. O., and Asparouhov, T. (2013, January 11). BSEM Measurement Invariance Analysis. Mplus Web Notes: No. 17. Available online at: http:// www.statmodel.com/examples/webnotes/webnote17.pdf (Accessed December 1, 2014).

Muthén, B. O., and Muthén, L. (2014). Mplus (Version 7.3) [Computer software]. Los Angeles, CA: Muthén u. Muthén.

Nagy, W., Berninger, V., and Abbott, R. (2006). Contributions of morphology beyond phonology to literacy outcomes of upper elementary and middle school students. J. Educ. Psychol. 98, 134-147. doi: 10.1037/0022-0663.98.1.134

OECD (2010). PISA 2009 Results: What Students Know and Can Do: Student Performance in Reading, Mathematics and Science, Vol. 1. Paris: OECD.

Pajares, F., and Valiente, G. (1999). Grade level and gender differences in the writing self-beliefs of middle school students. Contemp. Educ. Psychol. 24, 390-405. doi: 10.1006/ceps.1998.0995

Quenzel, G., and Hurrelmann, K. (2010). Geschlecht und Schulerfolg: ein soziales Stratifikationsmuster kehrt sich um [Gender and school performance: the inversion of a social stratification pattern]. Kölner Z. Soz. Sozialpsychol. 62, 61-91. doi: 10.1007/s11577-010-0091-4

Rimm-Kaufman, S. E., Curby, T. W., Grimm, K. J., Nathanson, L., and Brock, L. L. (2009). The contribution of children's self-regulation and classroom quality to children's adaptive behaviors in the kindergarten classroom. Dev. Psychol. 45, 958-972. doi: 10.1037/a0015861

Roman, A. A., Kirby, J. R., Parrila, R. K., Wade-Woolley, L., and Deacon, S. H. (2009). Toward a comprehensive view of the skills involved in word reading in Grades 4, 6, and 8. J. Exp. Child Psychol. 102, 96-113. doi: 10.1016/j.jecp.2008.01.004

Sabbagh, M. A., Xu, F., Carlson, S. M., Moses, L. J., and Lee, K. (2006). The development of executive functioning and theory of mind. Psychol. Sci. 17, 74-81. doi: 10.1111/j.1467-9280.2005.01667.x

Schicke, T., Bauer, F., and Röder, B. (2009). Interactions of different body parts in peripersonal space: how vision of the foot influences tactile perception at the hand. Exp. Brain Res. 192, 703-715. doi: 10.1007/s00221-008$1587-2$

Sheriston, L., Critten, S., and Jones, E. (2016). Routes to reading and spelling: testing the predictions of dual-route theory. Read. Res. Q. 51, 403-417. doi: $10.1002 /$ rrq. 143
Sobeh, J., and Spijkers, W. (2012). Development of attention functions in 5to 11-year-old Arab children as measured by the German Test Battery of Attention Performance (KITAP): a pilot study from Syria. Child Neuropsychol. 18, 144-167. doi: 10.1080/09297049.2011.594426

Sobeh, J., and Spijkers, W. (2013). Development of neuropsychological functions of attention in two cultures: a cross-cultural study of attentional performances of Syrian and German children of pre-school and school age. Eur. J. Dev. Psychol. 10, 318-336. doi: 10.1080/17405629.2012.674761

Spence, C., Kingstone, A., Shore, D. I., and Gazzaniga, M. S. (2001). Representation of visuotactile space in the split brain. Psychol. Sci. 12, 90-93. doi: 10.1111/1467-9280.00316

Sprenger-Charolles, L., Siegel, L. S., Béchennec, D., and Serniclaes, W. (2003). Development of phonological and orthographic processing in reading aloud, in silent reading, and spelling: a four-year longitudinal study. J. Exp. Child Psychol. 84, 194-217. doi: 10.1016/S0022-0965(03)00024-9

Temple, C. A., Nathan, R. G., and Burris, N. A. (1982). The Beginnings of Writing. Boston, MA: Allyn and Bacon, Inc.

Treiman, R., and Bourassa, D. C. (2000). The development of spelling skills. Top. Lang. Disord. 20, 1-18. doi: 10.1097/00011363-200020030-00004

Treiman, R., and Cassar, M. (1996). Effects of morphology on children's spelling of final consonant clusters. J. Exp. Child Psychol. 63, 141-170. doi: $10.1006 /$ jecp. 1996.0045

Valtin, R. (1997). "Strategies of spelling and reading of young children learning German orthography," in Cross-Language Studies of Learning to Read and Spell. Phonological and Orthographic Processing, eds C. K. Leong and R. M. Joshi (Dordrecht: Kluwer Academic Publishers), 175-193.

Van de Schoot, R., Lugtig, P., and Hox, J. (2012). A checklist for testing measurement invariance. Eur. J. Dev. Psychol. 9, 486-492. doi: 10.1080/17405629.2012.686740

van der Sluis, S., de Jong, P. F., and van der Leij, A. (2007). Executive functioning in children, and its relations with reasoning, reading, and arithmetic. Intelligence 35, 427-449. doi: 10.1016/j.intell.2006.09.001

von Suchodoletz, A., Larsen, R. A. Gunzenhauser, C., and Fäsche, A. (2015). Reading and spelling skills in German third graders: examining the role of student and context characteristics. Br. J. Educ. Psychol. 85, 533-550. doi: 10.1111/bjep.12090

von Suchodoletz, A., Slot, P. L., and Shroff, D. (2017). Measuring executive function in Indian mothers and their four-year-old daughters. PsyCh J. 6, 16-28. doi: 10.1002/pchj.156

Wanless, S. B., McClelland, M. M., Lan, X., Son, S.-H., Cameron, C. E., Morrison, F. J., et al. (2013). Gender differences in behavioral regulation in four societies: the U.S., Taiwan, South Korea, and China. Early Child. Res. Q. 28, 621-633. doi: 10.1016/j.ecresq.2013.04.002

Wilson, B. J. (2003). The role of attentional processes in children's prosocial behavior with peers: attention shifting and emotion. Dev. Psychopathol. 15, 313-329. doi: 10.1017/S0954579403000178

Yang, H., Yang, S., and Kang, C. (2014). The relationship between phonological awareness and executive attention in Chinese-English bilingual children. Cogn. Dev. 30, 65-80. doi: 10.1016/j.cogdev.2013.11.003

Yeong, S. H. M., Fletcher, J., and Bayliss, D. M. (2014). Importance of phonological and orthographic skills for English reading and spelling: a comparison of English monolingual and Mandarin-English bilingual children. J. Educ. Psychol. 106, 1107-1121. doi: 10.1037/a0036927

Zelazo (2006). The Dimensional Change Card Sort (DCCS): a method of assessing executive function in children. Nat. Protoc. 1, 297-301. doi: $10.1038 /$ nprot.2006.46

Conflict of Interest Statement: The authors declare that the research was conducted in the absence of any commercial or financial relationships that could be construed as a potential conflict of interest.

Copyright (๑) 2017 von Suchodoletz, Fäsche and Skuballa. This is an open-access article distributed under the terms of the Creative Commons Attribution License (CC $B Y$ ). The use, distribution or reproduction in other forums is permitted, provided the original author(s) or licensor are credited and that the original publication in this journal is cited, in accordance with accepted academic practice. No use, distribution or reproduction is permitted which does not comply with these terms. 